\title{
Developing a Department of Transportation Winter Severity Index
}

\author{
Curtis L. WAlker, ${ }^{\mathrm{a}}$ Dylan SteinKRuger, ${ }^{\mathrm{b}}$ Pouya GHOlizAdeh, ${ }^{\mathrm{c}}$ Sogand Hasanzedah, ${ }^{\mathrm{d}}$ \\ MARK R. ANDERSON, ${ }^{\mathrm{b}}$ AND BEHZAD ESMAEILI ${ }^{\mathrm{c}}$

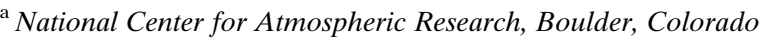 \\ ${ }^{\mathrm{b}}$ Department of Earth and Atmospheric Sciences, University of Nebraska-Lincoln, Lincoln, Nebraska \\ ${ }^{\mathrm{c}}$ Sid and Reva Dewberry Department of Civil, Environmental and Infrastructure Engineering, George Mason \\ University, Fairfax, Virginia \\ ${ }^{\mathrm{d}}$ Charles E. Via, Jr., Department of Civil and Environmental Engineering, Virginia Polytechnic Institute and State \\ University, Blacksburg, Virginia
}

(Manuscript received 19 September 2018, in final form 20 June 2019)

\begin{abstract}
Adverse weather conditions are responsible for millions of vehicular crashes, thousands of deaths, and billions of dollars per year in economic and congestion costs. Many transportation agencies utilize a performance or mobility metric to assess how well they maintain road access; however, there is only limited consideration of meteorological impacts to the success of their operations. This research develops the Nebraska winter severity index (NEWINS), which is a daily event-driven index derived for the Nebraska Department of Transportation (NDOT). The NEWINS includes a categorical storm classification framework to capture atmospheric conditions and possible road impacts across diverse spatial regions of Nebraska. A 10-yr (2006-16) winter season database of meteorological variables for Nebraska was obtained from the National Centers for Environmental Information. The NEWINS is based on a weighted linear combination applied to the collected storm classification database to measure severity. The NEWINS results were compared to other meteorological variables, many used in other agencies' winter severity indices. This comparison verified the NEWINS robustness for the observed events for the 10-yr period. An assessment of the difference between days with observed snow versus days with accumulated snow revealed $39 \%$ fewer snow-accumulated days than snow-observed days. Furthermore, the NEWINS results highlighted the greater number of events during the 2009/10 winter season and the lack of events during the 2011/12 winter season. It is expected that the NEWINS could help transportation personnel allocate efficiently resources during adverse weather events. Moreover, the NEWINS framework can be used by other agencies to assess their weather sensitivity.
\end{abstract}

\section{Introduction}

Adverse cold weather conditions, most notably snow and ice, threaten surface transportation nationwide and impact roadway safety, mobility, and maintenance costs [Pisano et al. 2008; Black and Mote 2015a,b; Road Weather Management Program (RWMP) 2018]. During the period from 2005 to 2014, weather-related vehicular crashes accounted for $22 \%$ (1258978) of all reported crashes, resulting in $16 \%$ (5897) of crash fatalities and $19 \%$ (445303) of crash injuries (RWMP 2018). The U.S. Department of Transportation (USDOT) National Highway Traffic Safety Administration (NHTSA) estimated the total economic and societal cost of all vehicular crashes in 2010 in the United States was $\$ 836$

Corresponding author: Curtis L. Walker, walker@ucar.edu billion (Blincoe et al. 2015; NHTSA 2018). This total included $\$ 242$ billion in maintenance and congestion costs and $\$ 594$ billion from injuries and loss of life. Weather-related vehicular crashes alone may account for approximately $\$ 180$ billion nationwide, given the relative percentage of such crashes.

Snow and ice reduce pavement friction and vehicle maneuverability, causing slower traffic speeds and reducing roadway capacity. In fact, on snowy or slushy pavement, average arterial speeds decline by $30 \%-40 \%$ (RWMP 2018). Highway speeds are reduced by $3 \%-13 \%$ in light snow and by $5 \%-40 \%$ in heavy snow (RWMP 2018). In addition to this reduction in speed, lanes and roads can be obstructed by snow accumulation, which reduces capacity (i.e., traffic counts; Call 2011) and increases travel time delay. Snow and ice also increase road maintenance costs. Winter road maintenance accounts 
for roughly $20 \%$ of state departments of transportation (DOTs) maintenance budgets (RWMP 2018). Annually, state and local agencies spend more than two billion dollars on snow and ice control operations and millions of dollars to repair infrastructure damage caused by snow and ice (RWMP 2018). Given the impact to safety and high economic costs of adverse cold weather events, it is prudent to mitigate the impacts of such events on roadways and allocate resources to reduce their severity. However, state DOTs face increasing pressure to ensure resource efficiency with limited budgets. Ensuring optimized mitigation strategies is key to maintaining the road network with efficient use of resources.

Evaluating the performance of mitigation strategies implemented as part of winter maintenance operations requires consideration of weather conditions, the state of the road network, the maintenance efforts undertaken for a given storm, the resulting road conditions, and the interactions among these factors. The main challenge in evaluating this performance is that weather is inherently variable, and its variability complicates assessments of the relative efficiency and effectiveness of different winter maintenance operations (e.g., meeting levels of service standards, salt reduction, budget targets). Therefore, in pursuit of an evaluation metric for winter maintenance operations, a critical need is to assess the severity of individual storms through a winter severity index (WSI).

The literature documenting existing WSIs depicts myriad approaches typically developed for specific state DOTs (Boselly et al. 1993; Strong et al. 2005; Jensen et al. 2013; Blincoe et al. 2015; Walsh 2016; Walker et al. 2019). In total, 19 states have made available documentation regarding their WSI. In addition to these, Connecticut and Vermont have winter severity indices presently in development (Kipp and Sanborn 2013; Mahoney et al. 2015). Existing WSIs often were developed with relatively small datasets (e.g., less than six locations) and/or limited time frames (e.g., single month and/or winter season), with some noteworthy exceptions (Strong et al. 2005). Few WSIs have considered a winter storm classification framework (i.e., consideration of individual storm type/variables vs agglomeration throughout entire winter season), though several winter storm classification schemes exist (e.g., Kocin and Uccellini 2004; Cerruti and Decker 2011). Automated Surface Observing System (ASOS) stations serve as the primary source for many WSIs, in addition to Road Weather Information System (RWIS) stations (Strong et al. 2005). As such, air and road temperatures, snowfall, wind, and freezing rain data are the most common/important variable inclusions in WSI development.
Many existing WSIs have been developed specifically for transportation-related purposes over relatively short time scales. Nontransportation WSIs have been developed for a wide array of uses, such as deer hunting [Minnesota Department of Natural Resources (MNDNR) 2018], and are beyond the scope of this work; however, other meteorological WSIs with no specific intended use are mentioned herein. The accumulated winter season severity index (AWSSI; Boustead et al. 2015) represents a purely climatologybased meteorological WSI. The AWSSI was developed initially for over 50 locations in the United States to provide seasonal winter severity values during the period from 1950 through present day [Midwestern Regional Climate Center (MRCC) 2018]. Daily points are assigned for specific locations in the AWSSI for predefined thresholds of minimum and maximum air temperatures, snowfall amounts, and snow depth. These points are accumulated for an entire winter season to produce a final score that is associated with a given location's winter severity. These final scores are sorted into a categorical range to report final classifications (mild, moderate, average, severe, and extreme). While the AWSSI is a temporally robust WSI, an important limitation is that it is computed on a point-by-point basis. It would be necessary to interpolate winter severity values between points computed by the AWSSI. Another caveat of the AWSSI is that it assesses conditions throughout the entire winter season, not specific to an individual winter storm. This aligns with many of the state DOT WSIs, as well; however, winter maintenance operations are more aligned with specific events rather than an entire winter season.

The National Weather Service (NWS) is experimenting with a prototype winter storm severity index [WSSI; Weather Prediction Center (WPC) 2018] to better communicate impacts associated with winter storms as part of its strategic plan, which calls for an increase in decision support services (Rutz and Gibson 2013). The WSSI uses a categorical framework to discuss storm severity and impacts (none, limited, minor, moderate, major, and extreme). Unlike the AWSSI and many state DOT WSIs, the WSSI is specific to individual snowstorms. The components of the WSSI include snow amount, blowing snow, ice accumulation, flash freeze, and ground blizzard. A daily event-driven, meteorological index complements the ongoing refinement of the WSSI.

This current analysis developed a WSI for the Nebraska Department of Transportation (NDOT). The Nebraska winter severity index (NEWINS; pronounced "N-wins") incorporates various statewide surface and atmospheric data across a 10-yr period from July 2006 through June 2016. Road temperature and freezing rain 


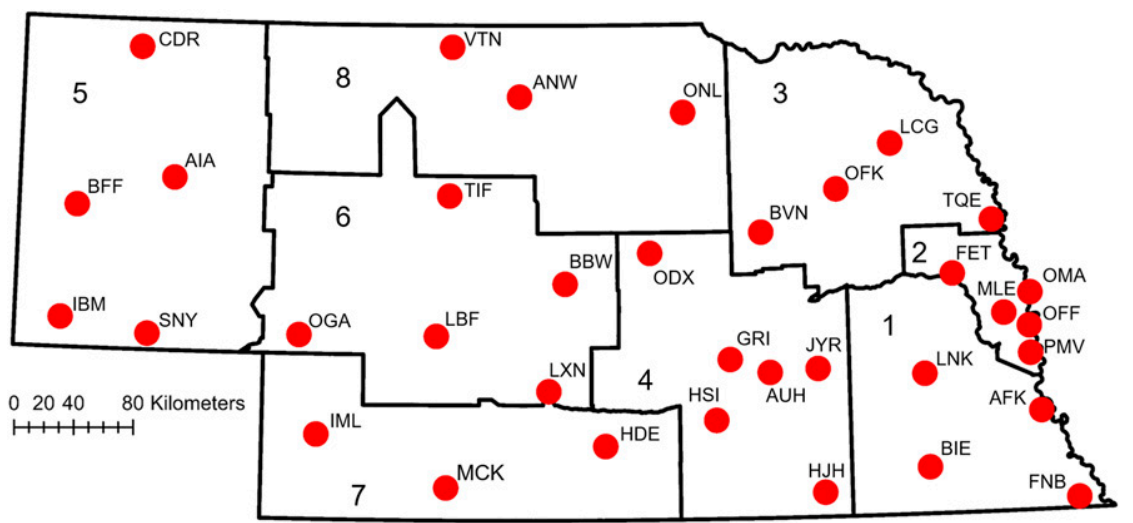

FIG. 1. State of Nebraska with eight Nebraska Department of Transportation (NDOT) maintenance districts outlined in the thick black line. The 35 red dots indicate Automated Surface Observing System (ASOS) stations with additional information in Table 1.

data are omitted from the development of the NEWINS, despite their desirability, because of their lack of reliability and availability for the entire 10 -yr study period. From these data and subsequent analyses, a single statewide value for each of the 10 winter seasons was computed. The strength of the NEWINS is that it independently and explicitly considers the individual contribution of select meteorological parameters spatiotemporally during each event, and the combined influence of these parameters, which yields a storm classification frequency distribution that is accumulated throughout a winter season. The NEWINS provides a finer resolution than most existing WSIs by considering storm-level data. Furthermore, the NEWINS focuses on meteorological conditions and can subsequently be compared independently with transportation and winter maintenance data.

\section{Data and methodology}

The development of the NEWINS first considers the study region and datasets used to define the winter season database. A winter season is defined from 1 July of the first year to 30 June of the subsequent year. For example, snowfall occurring from 1 July 2006 through 30 June 2007 would represent the 2006/07 winter season. Next, data management and quality control criteria were established to ensure a high-quality dataset. Individual events were classified in accordance with the NEWINS categorical framework. Last, the NEWINS was computed for the entire state of Nebraska, in addition to its individual transportation maintenance districts within the state, and validated against winter maintenance performance data.

\section{a. Study region and data}

The study region for the development of the NEWINS was defined by the state boundaries of Nebraska and the eight NDOT maintenance districts (Fig. 1). Atmospheric variables for the NEWINS were obtained from the National Oceanic and Atmospheric Administration (NOAA) National Centers for Environmental Information (NCEI) for all ASOS stations within Nebraska (NCEI 2017a). Hourly data obtained from the ASOS stations included station name, station elevation, station latitude, station longitude, wind speed, wind gust speed, wind direction, cloud cover, visibility, present observed weather, air temperature, dewpoint temperature, sea level pressure, station pressure, and liquid-equivalent precipitation every hour, six hours, and $24 \mathrm{~h}$ (NCEI 2017a; NWS 2018a).

Snowfall observations for the NEWINS were obtained from the Global Historical Climatology Network-Daily (GHCN-D) sites within Nebraska (NCEI 2017b). The GHCN-D sites include data from the Community Collaborative Rain, Hail, and Snow Network (CoCoRaHS 2018), the Nebraska Rainfall Assessment and Information Network (NeRAIN 2018), and the NWS Cooperative Observer Network (NWS 2018b) observations. There are approximately $1000 \mathrm{GHCN}-\mathrm{D}$ sites statewide. The majority of the GHCN-D sites record once-daily, 24-h snowfall amounts measured at approximately 0700 local time (LT); however, there can be some temporal variability in the actual measurement time. Given this variability, it is necessary to define a more consistent daily event period.

\section{b. Data management and quality control}

The abundance of data and having an objective to ensure stringent criteria for the analysis required quality control procedures prior to the development of the NEWINS. Initially, 39 ASOS stations were included in the analysis; however, the quality control procedures reduced this number to 35 stations (Table 1). Four 
TABLE 1. Automated Surface Observing System (ASOS) station information organized by NDOT maintenance district. The spatial distribution of these stations is shown in Fig. 1. Removed column identifies stations omitted from the analysis after quality control.

\begin{tabular}{|c|c|c|c|c|c|c|c|c|}
\hline NDOT district & Station ID & City name & USAF ID & Lat $\left(^{\circ}\right)$ & Lon $\left(^{\circ}\right)$ & Elev (m) & Time zone & Removed \\
\hline 1 & BIE & Beatrice & 725515 & 40.28 & -96.75 & 403 & Central & \\
\hline 1 & FNB & Falls City & 725533 & 40.07 & -95.58 & 300 & Central & \\
\hline 1 & LNK & Lincoln & 725510 & 40.85 & -96.77 & 364 & Central & \\
\hline 1 & AFK & Nebraska City & 725541 & 40.60 & -95.85 & 354 & Central & \\
\hline 1 & AHQ & Wahoo & 720942 & 41.23 & -96.60 & 374 & Central & $x$ \\
\hline 2 & BTA & Blair & 720405 & 41.42 & -96.12 & 396 & Central & $\times$ \\
\hline 2 & FET & Fremont & 725564 & 41.45 & -96.52 & 367 & Central & \\
\hline 2 & OFF & Bellevue & 725540 & 41.12 & -95.92 & 319 & Central & \\
\hline 2 & OMA & Omaha & 725500 & 41.32 & -95.90 & 312 & Central & \\
\hline 2 & MLE & Millard & 720308 & 41.20 & -96.12 & 320 & Central & \\
\hline 2 & PMV & Plattsmouth & 722291 & 40.95 & -95.92 & 367 & Central & \\
\hline 3 & $\mathrm{BVN}$ & Albion & 723441 & 41.73 & -98.05 & 551 & Central & \\
\hline 3 & OLU & Columbus & 725565 & 41.45 & -97.32 & 440 & Central & $\times$ \\
\hline 3 & OFK & Norfolk & 725560 & 41.98 & -97.43 & 470 & Central & \\
\hline 3 & TQE & Tekamah & 725527 & 41.77 & -96.18 & 312 & Central & \\
\hline 3 & LCG & Wayne & 722241 & 42.25 & -96.98 & 436 & Central & \\
\hline 4 & AUH & Aurora & 725513 & 40.88 & -98.00 & 550 & Central & \\
\hline 4 & GRI & Grand Island & 725520 & 40.97 & -98.32 & 561 & Central & \\
\hline 4 & HSI & Hastings & 725525 & 40.60 & -98.43 & 591 & Central & \\
\hline 4 & HJH & Hebron & 722124 & 40.15 & -97.58 & 447 & Central & \\
\hline 4 & EAR & Kearney & 725526 & 40.72 & -99.00 & 649 & Central & $\times$ \\
\hline 4 & ODX & Ord & 725524 & 41.62 & -98.95 & 631 & Central & \\
\hline 4 & JYR & York & 725512 & 40.90 & -97.62 & 509 & Central & \\
\hline 5 & AIA & Alliance & 725635 & 42.05 & -102.80 & 1196 & Mountain & \\
\hline 5 & CDR & Chadron & 725636 & 42.83 & -103.10 & 1010 & Mountain & \\
\hline 5 & IBM & Kimball & 725665 & 41.18 & -103.68 & 1501 & Mountain & \\
\hline 5 & $\mathrm{BFF}$ & Scottsbluff & 725660 & 41.87 & -103.58 & 1203 & Mountain & \\
\hline 5 & SNY & Sidney & 725610 & 41.10 & -102.98 & 1307 & Mountain & \\
\hline 6 & BBW & Broken Bow & 725555 & 41.43 & -99.63 & 776 & Central & \\
\hline 6 & LXN & Lexington & 725624 & 40.78 & -99.77 & 734 & Central & \\
\hline 6 & $\mathrm{LBF}$ & North Platte & 725620 & 41.12 & -100.67 & 847 & Central & \\
\hline 6 & OGA & Ogallala & 725621 & 41.12 & -101.77 & 999 & Mountain & \\
\hline 6 & TIF & Thedford & 722211 & 41.97 & -100.57 & 892 & Central & \\
\hline 7 & HDE & Holdrege & 725628 & 40.45 & -99.32 & 705 & Central & \\
\hline 7 & IML & Imperial & 725626 & 40.52 & -101.62 & 998 & Mountain & \\
\hline 7 & MCK & McCook & 725625 & 40.20 & -100.58 & 782 & Central & \\
\hline 8 & ANW & Ainsworth & 725556 & 42.57 & -100.00 & 789 & Central & \\
\hline 8 & ONL & O’Neill & 725566 & 42.47 & -98.67 & 619 & Central & \\
\hline 8 & VTN & Valentine & 725670 & 42.87 & -100.55 & 788 & Central & \\
\hline
\end{tabular}

ASOS stations were removed from the analysis because either 1) the station did not have an operational precipitation identification sensor (PI) for all or part of the 10-yr period [Columbus (KOLU) and Kearney (KEAR)] or 2) the station had missing data for more than one entire winter season [Blair (KBTA) and Wahoo (KAHQ)]. Plattsmouth (KPMV; 2014/15) and Wayne (KLCG; 2013/14) each had a single winter season in which no data were available; however, the stations were included in the overall analysis. After quality control, the number of ASOS stations per NDOT district ranged from three stations in districts 7 and 8 to six stations in district 4 (Fig. 1). Spatially, the ASOS stations were distributed throughout the NDOT districts to capture the range of spatial variability in atmospheric conditions.
Hourly ASOS station observations were only incorporated into the analyses if the PI detected frozen precipitation (snow, ice pellets, or mixed precipitation). Freezing rain was not considered in the analyses because of challenges associated with verifying ice accumulation (Changnon and Creech 2003) on spatiotemporal scales necessary for the research objective. For any 24-h period, it is possible for only a single hour of observations to be included if that was the only instance of frozen precipitation identified. It is also possible for several discontinuous or continuous hours to be included if the precipitation was more intermittent or steady, respectively.

Quality control for these hourly frozen precipitation observations included computing dewpoint depression 
(i.e., difference between observed air and dewpoint temperatures). Hourly observations were removed from the winter season database if their dewpoint depression exceeded $30^{\circ} \mathrm{F}\left(16.7^{\circ} \mathrm{C}\right)$. As noted by Jiusto and Weickmann (1973), extreme dewpoint depressions would not yield adequate moisture availability for frozen precipitation. It is believed that such extreme dewpoint depressions would be either the result of sensor error or indicative of exceptionally light snowfall.

The GHCN-D sites used in the analysis were only selected if the observation was within an approximate 9-mi $(15 \mathrm{~km})$ spatial threshold of an ASOS station. This was intended to ensure spatial consistency between the observed snowfall and the atmospheric conditions present during the snow accumulation period. Given the interest in snowfall amounts that would require a winter maintenance operations response (i.e., plowing of measurable snow), GHCN-D sites were removed if the snowfall observations were either missing or reported as a trace. To be included in the NEWINS winter season database, GHCN-D sites had to report a measurable snowfall amount.

After quality control, the ASOS station and GHCN-D site data were merged into a winter season event database. For each date, hourly ASOS station observations in which frozen precipitation was detected were paired with 24-h snowfall amounts from the GHCN-D sites that adhered to the spatial and temporal criteria. The snowfall observations and number of hours of ASOS station data for each date and location pair were used to derive a snowfall rate variable by dividing snowfall amounts by the number of hours with frozen precipitation observed. It is important to note that this snowfall rate provides only a rough approximation and represents an important limitation of the parameter, as actual rates vary significantly during the period of snowfall. Because of the derived nature of the snowfall rate variable, rates in excess of $3 \mathrm{in} . \mathrm{h}^{-1}\left(7.62 \mathrm{~cm} \mathrm{~h}^{-1}\right)$ were removed, given the climatological infrequency of such extreme rates in Nebraska as previously documented by Rasmussen et al. (1999). Another derived variable was "district area," which can provide a spatial context for the snowfall. District area was computed by dividing the number of ASOS stations reporting frozen precipitation on a given date in a particular NDOT maintenance district by the total number of ASOS stations possible within that district. Statistical parameters (i.e., minimum, maximum, mean, and median) were computed for all of the available variables from the ASOS stations, GHCN-D sites and derived variables.

\section{c. Event classification}

In close consultation with NDOT, the following variables were selected for the development of the
NEWINS: 1) wind speed, 2) visibility, 3) air temperature, 4) duration of snowfall, 5) daily snowfall, 6) snowfall rate, and 7) district area. These variables were selected on the basis of their reliability from the instrumentation in addition to their importance/impact on NDOT's winter maintenance operations. For inclusion in the winter season database, these weather variables were averaged across each NDOT maintenance district from the available merged ASOS station and GHCN-D site data for each date. Road surface (i.e., RWIS stations) temperature data were not sufficiently quality controlled (Walker and Anderson 2016) and were not available for the entire historical 10-yr period; therefore, they were not included in the development of the NEWINS.

NDOT communicates extensively with its local NWS offices, and it was desirable to create a winter severity index that mirrored existing and possible future NWS products such as the Storm Prediction Center (SPC) convective outlook severe thunderstorm risk categories (SPC 2016), experimental winter storm threat graphics (NWS 2016), or experimental winter storm severity index (WPC 2018). To this end, in consultation with NDOT, a categorical road weather and winter maintenance operations framework was developed to serve as the foundation for NEWINS (Fig. 2). The objective was to classify individual events within the winter season database into one of six categories from category 1 (i.e., trace, low impact storms, no winter maintenance operations activity) to category 6 (i.e., high, significant impact storms, maximum winter maintenance operations activity with possible operations suspensions necessary because of safety concerns). This categorical framework was designed with specific consideration given to 1) road access, 2) road conditions, 3) traffic speeds, 4) treatment operations, and 5) NDOT's winter maintenance performance objective. Road access is defined here as whether the road is open and travel by the public is permitted. Road condition refers to the amount and type of precipitation accumulation within the driving lanes, ranging from wet roads to impassable because of snow and ice coverage. Traffic speed addresses the likely impact of the weather conditions on free-flow travel speeds. NDOT does not consider specific speed thresholds as a prerequisite to define a meteorological impact, as impacts can occur at any speed (NDOT 2016, personal communication). Treatment operations refers to NDOT's winter maintenance activities, including but not limited to chemical or material applications and mechanical plowing for snow removal. Finally, NDOT's maintenance performance objective is to return roadway speeds to within $10 \mathrm{mph}\left(16 \mathrm{~km} \mathrm{~h}^{-1}\right)$ of the posted speed limit within six hours of precipitation cessation 


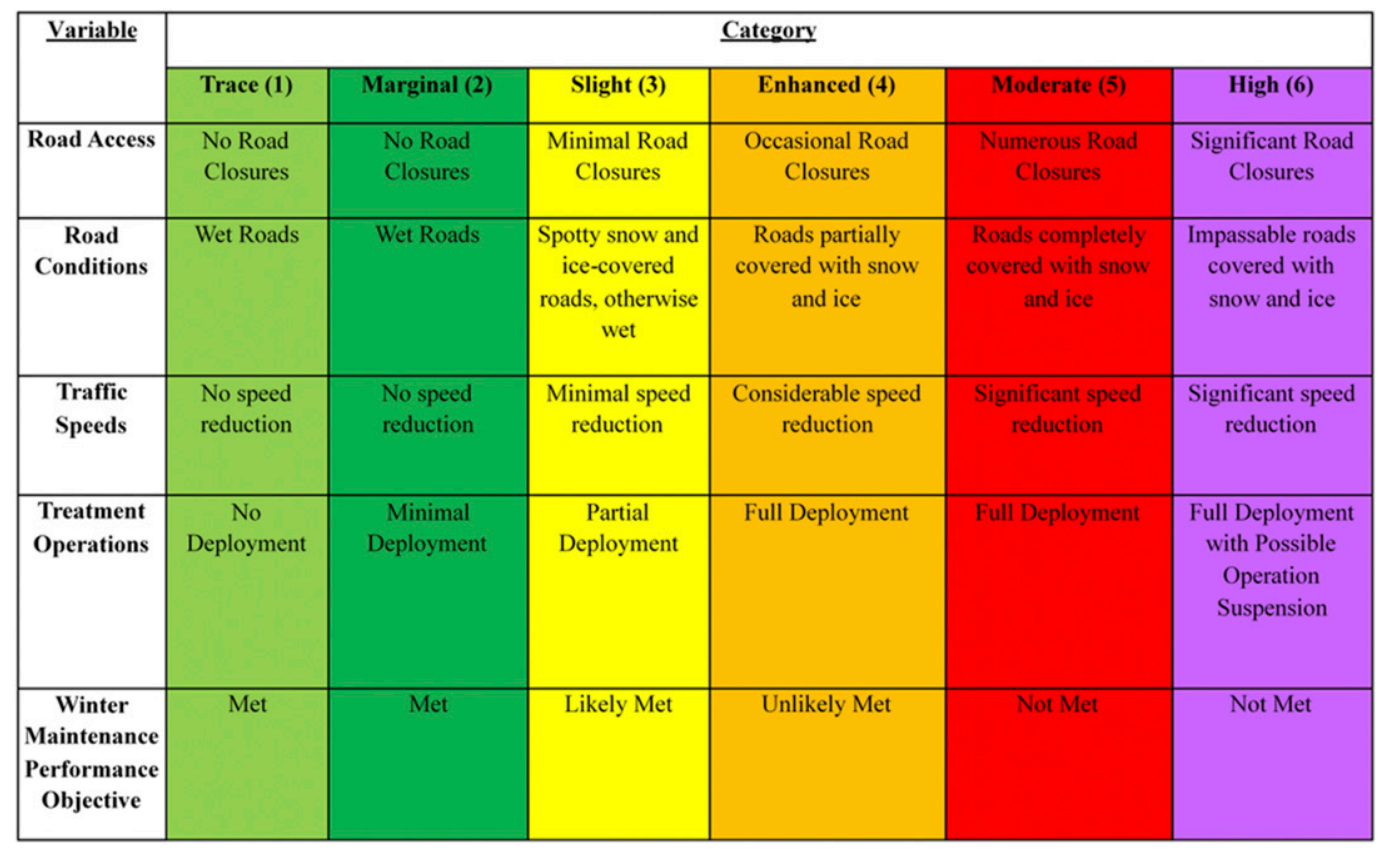

FIG. 2. Nebraska winter severity index (NEWINS) categorical road and winter maintenance operations impacts.

(NDOT 2016, personal communication). The likelihood of attaining that objective is incorporated into the NEWINS categorical framework.

Seven weather variables selected for the NEWINS were placed into the road weather/maintenance operations categorical framework with significant input from NDOT concerning their winter maintenance operations (Fig. 3). Snowfall, air temperature, and district area were distributed among the six categories to ensure near-even separation across the range of each variable. For example, each snowfall category range varies between 1 and 2 in. $(2.5-5.1 \mathrm{~cm})$ or each air temperature category contained a $5^{\circ} \mathrm{F}\left(2.8^{\circ} \mathrm{C}\right)$ range, excluding the minimum and maximum categories. Snowfall rate, snowfall duration, and visibility were distributed among the six categories to ensure near-even frequency of observations within each category. Last, wind speed was distributed among the six categories loosely based on a modified Beaufort wind scale (SPC 2018). Figure 3 shows the specific distribution of each weather variable and its categorical assignment resultant from iterations with NDOT. It is important to note that each weather variable is averaged across the maintenance district only during periods of snow and assigned a category based on Fig. 3. These ranges do not represent a single, 1-min-averaged observation at any one location but rather a daily, district-averaged value. For example, one may note that the most severe visibility category has a threshold of less than $2.5 \mathrm{mi}$, which is a broad range of visibilities including those that are typical of blizzard conditions ( $0.25 \mathrm{mi}$ or less). Given the spatial districtlevel averaging, such low visibilities that may be observed at a particular location in time are generally not observed in the overall winter season database. Expanded discussion on these distributions is provided in Walker (2018). Cerruti and Decker (2011) proposed a similar approach in the development of their local winter storm scale (LWSS).

The NEWINS joins an array of WSIs, each with their own respective strengths and caveats. As seen from Boselly et al. (1993), the best approach is for a WSI to be tailored specifically to the needs of the state DOT; broad, versatile WSIs are often inapplicable because of their simplicity or lack of accounting for localized conditions and expectations. Given that the NEWINS was designed with respect to a decadal winter season database, it exceeds the index created by Boselly et al. (1993) in terms of considering local and regional weather variability. Given the 10-yr development period, the NEWINS is exceeded only by the AWSSI (Boustead et al. 2015) in terms of its historical period. With the inclusion of 35 ASOS stations distributed throughout eight transportation districts, the NEWINS provides a greater station density than the AWSSI, which considered approximately 50 locations throughout the United States at the time of its development. Important differences between the NEWINS and AWSSI are that the NEWINS averages conditions across all ASOS stations within each district and throughout the state to derive a categorical frequency distribution and subsequent 


\begin{tabular}{|c|c|c|c|c|c|c|}
\hline \multirow{2}{*}{$\underline{\text { Variable }}$} & \multicolumn{6}{|c|}{ Category } \\
\hline & Trace (1) & Marginal (2) & Slight (3) & Enhanced (4) & Moderate (5) & High (6) \\
\hline $\begin{array}{c}\text { Snowfall } \\
\text { (in) } \\
(\mathrm{cm})\end{array}$ & $\begin{array}{l}\text { Dusting } \\
<1.0 \\
(<2.4)\end{array}$ & $\begin{array}{l}\text { Light } \\
<2.0 \\
(<4.9)\end{array}$ & $\begin{array}{l}\text { Light } \\
<3.0 \\
(<7.5)\end{array}$ & $\begin{array}{c}\text { Considerable } \\
<5.0 \\
(<12.6)\end{array}$ & $\begin{array}{l}\text { Heavy } \\
<7.0 \\
(<17.5)\end{array}$ & $\begin{array}{l}\text { Significant } \\
\geq 7.0 \\
\geq 17.5)\end{array}$ \\
\hline 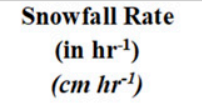 & $\begin{array}{l}\text { Minor } \\
<0.2 \\
(<0.4)\end{array}$ & $\begin{array}{c}\text { Minor } \\
0.2 \\
(<0.6)\end{array}$ & $\begin{array}{c}\text { Elevated } \\
0.3 \\
(<0.9)\end{array}$ & $\begin{array}{c}\text { Elevated } \\
0.4 \\
(<1.1)\end{array}$ & $\begin{array}{l}\text { Intense } \\
<0.6 \\
(<1.5)\end{array}$ & $\begin{array}{c}\text { Extreme } \\
\geq 0.6 \\
(\geq 1.5)\end{array}$ \\
\hline $\begin{array}{c}\text { Wind Speed } \\
(\mathrm{mph}) \\
\left(m s^{-1}\right)\end{array}$ & $\begin{array}{l}\text { Light } \\
\leq 6.0 \\
(\leq 2.7)\end{array}$ & $\begin{array}{l}\text { Light } \\
\leq 11.0 \\
(\leq 4.9)\end{array}$ & $\begin{array}{l}\text { Moderate } \\
\leq 18.0 \\
(\leq 8.1)\end{array}$ & $\begin{array}{l}\text { Moderate } \\
\leq 24.0 \\
(\leq 10.7)\end{array}$ & $\begin{array}{l}\text { Strong } \\
\leq 31.0 \\
(\leq 13.9)\end{array}$ & $\begin{array}{l}\text { Strong } \\
>31.0 \\
(>13.9)\end{array}$ \\
\hline $\begin{array}{c}\text { Air Temperature } \\
\left({ }^{\circ} \mathbf{F}\right) \\
\left({ }^{\circ} \mathrm{C}\right)\end{array}$ & $\begin{array}{c}\text { Above } \\
\text { Freezing } \\
>35 \\
(>1.7)\end{array}$ & $\begin{array}{l}\text { Near / Below } \\
\text { Freezing } \\
\leq 35 \\
(\leq 1.7)\end{array}$ & $\begin{array}{c}\text { Below Freezing } \\
\quad \leq 29 \\
(\leq-1.7)\end{array}$ & $\begin{array}{c}\text { Below Freezing } \\
\leq 25 \\
(\leq-3.9)\end{array}$ & $\begin{array}{c}\text { Below Freezing } \\
\quad \leq 19 \\
(\leq-7.2)\end{array}$ & $\begin{array}{c}\text { Well Below } \\
\text { Freezing } \\
<15 \\
(<-9.4)\end{array}$ \\
\hline $\begin{array}{c}\text { District Area } \\
\text { (Fraction Area) }\end{array}$ & $\begin{array}{l}\text { Single } \\
\text { Location } \\
\leq 0.2\end{array}$ & $\begin{array}{c}\text { Partial } \\
<0.4\end{array}$ & $\begin{array}{c}\text { Less Than Half } \\
<0.5\end{array}$ & $\begin{array}{c}\text { More Than Half } \\
<0.75\end{array}$ & $\begin{array}{c}\text { Majority } \\
<1.0\end{array}$ & $\begin{array}{c}\text { Complete } \\
1.0\end{array}$ \\
\hline Duration (hr) & $\begin{array}{l}\text { Short } \\
\leq 2.0\end{array}$ & $\begin{array}{l}\text { Short } \\
\leq 3.0\end{array}$ & $\begin{array}{l}\text { Medium } \\
\leq 4.0\end{array}$ & $\begin{array}{c}\text { Medium } \\
\leq 5.0\end{array}$ & $\begin{array}{l}\text { Long } \\
\leq 8.0\end{array}$ & $\begin{array}{l}\text { Long } \\
>8.0\end{array}$ \\
\hline $\begin{array}{c}\text { Visibility } \\
\text { (mi) } \\
(\mathrm{km})\end{array}$ & $\begin{array}{l}\text { Good } \\
>5.0 \\
(>8.0)\end{array}$ & $\begin{array}{c}\text { Good } \\
\leq 5.0 \\
(\leq 8.0)\end{array}$ & $\begin{array}{l}\text { Fair } \\
<4.0 \\
(<6.4)\end{array}$ & $\begin{array}{c}\text { Mid-Range } \\
\quad<3.5 \\
(<5.6)\end{array}$ & $\begin{array}{c}\text { Poor } \\
<3 \\
(<4.8)\end{array}$ & $\begin{array}{c}\text { Poor } \\
<2.5 \\
(<4.0)\end{array}$ \\
\hline
\end{tabular}

FIG. 3. NEWINS categorical weather variable impacts provide a qualitative, transferrable framework. NEWINS weather variable categorical classification assignment provides the specific quantitative ranges used specifically in Nebraska. The categories are obtained from district-wide averages of each weather variables during only the periods of observed snowfall.

severity value. By comparison, the AWSSI computes a severity value for point locations (Boustead et al. 2015). Another important difference is that the AWSSI considers daily conditions throughout the entire winter season, whereas the NEWINS considers the conditions and impacts associated with specific snowstorms. One final difference is that the AWSSI establishes strict criteria to define the beginning and end of a winter season, whereas the NEWINS is more flexible and allows for the precipitation type (i.e., frozen precipitation) to dictate the temporal boundaries of the winter season. Both approaches are transferrable to other applications.

\section{d. Winter severity index computation and applications}

An important challenge to overcome with the categorical framework is that for any given event during a winter season, the magnitude of the weather variables can be quite different for a single maintenance district or across several maintenance districts during the same event. In consultation with NDOT, appropriate weights for the seven weather variables were developed so that a linear combination would yield a single storm categorical classification (Fig. 2) for each event at the district level. Each weather variable is averaged across the maintenance district and assigned a category based on Fig. 3. Categories for each weather variable are subsequently used in lieu of the raw data for the general form of the NEWINS event category. The resulting linear combination in Eq. (1) provides a value for the severity of the winter storm:

$$
\text { Category }=\sum_{N=1}^{7}\left(\beta_{N} \times \mathrm{WVC}_{N}\right),
$$

where $N$ varies from 1 to 7 for each of the 7 defined weather variables, $\beta$ is the weight assigned to weather variable $N$ by Table 2, and WVC is the weather variable category assigned to weather variable $N$ by Fig. 3 .

From the categorical frequency distribution, the final NEWINS value is computed according to Eq. (2):

$$
\text { NEWINS }=\frac{\sum(\text { Category } \times \text { Frequency })}{100} .
$$

This provides the final statewide NEWINS value for a given season. It can also be used to compute an 
TABLE 2. NEWINS event category linear combination equation weights.

\begin{tabular}{lc}
\hline \multicolumn{1}{c}{ Parameter } & NEWINS parameter weight \\
\hline Snowfall category $\left(\beta_{1}\right)$ & 0.80 \\
Snow rate category $\left(\beta_{2}\right)$ & 0.05 \\
Wind speed category $\left(\beta_{3}\right)$ & 0.05 \\
Air temperature category $\left(\beta_{4}\right)$ & 0.05 \\
District area category $\left(\beta_{5}\right)$ & 0.02 \\
Duration category $\left(\beta_{6}\right)$ & 0.02 \\
Visibility category $\left(\beta_{7}\right)$ & 0.01 \\
\hline
\end{tabular}

NEWINS value for each individual NDOT maintenance district, which can be summed to yield the same final statewide value. The mathematical linear combination/parameter weighting of the NEWINS is similar to those used by Wisconsin, Minnesota, Indiana, Illinois, and Pennsylvania for their respective WSIs (Cohen 1981; Strong et al. 2005). An important difference is that the NEWINS incorporates a categorical classification for individual snowstorms similar to Iowa (Carmichael et al. 2004; Nixon and Qiu 2005; Strong et al. 2005; Qui 2008; Walsh 2016). Limitations of Iowa's WSI for application in Nebraska, though, are that it does not consider a complete set of relevant variables important to winter maintenance operations (e.g., areal coverage, duration, snowfall rate, visibility). In terms of a dependent variable, the NEWINS is substantially different from the California, Montana, Oregon, Idaho, and Colorado WSIs (Strong et al. 2005; Jensen et al. 2013; Walsh 2016) in that it is a pure meteorological index (like the AWSSI) and not related to accident rate or grip measurements. It is feasible to correlate the NEWINS to transportation-related variables in the future; however, no such data are presently available over the entire historical period.

To ensure the reliability of the NEWINS and its components, several different indices were computed and subsequently compared to the NEWINS. An initial snow-based index was computed statewide and for each NDOT maintenance district by comparing the number of days with observed frozen precipitation as identified from the ASOS station data (snow-observed days) to the number of days with observed snow accumulation as identified from the GHCN-D site data (snow-accumulated days). A second snow-based index was computed statewide and for each maintenance district comparing each winter season's total accumulated snowfall to the 10-yr average snowfall accumulation. For an independent climate-based index, temperature and precipitation anomalies were obtained from the NOAA NCEI climate division data [Earth System Research Laboratory (ESRL) 2017; Climate Prediction Center
(CPC) 2018]. Nebraska contains eight climate districts that roughly align with NDOT's eight maintenance districts. Additionally, an application of the NEWINS was performed by comparing the results of the 2015/16 winter season storm classification to available NDOT traffic speed data.

\section{Results and discussion}

Multiple steps led to the development of the NEWINS, and their results are presented by subsections within this section. To provide context and highlight the strengths of the NEWINS, the first task was a comparison analysis of various meteorological indices. The second task was the development and refinement of the NEWINS event classification and mathematical formulas. The third task provided a more in-depth consideration of the NEWINS at the statewide and district levels given the intended use of the NEWINS by NDOT. To apply the NEWINS, the final task compared the NEWINS to 2015/16 winter maintenance performance data across NDOT's Interstate 80 test sections.

\section{a. Snow comparison indices}

Comparison indices were computed to provide additional context for the NEWINS. Some severity indices (e.g., Cohen 1981; Kocin and Uccellini 2004; Strong et al. 2005) consider the spatial distribution of accumulated snowfall throughout an event or entire winter season. Therefore, snow-based indices were computed statewide and for each NDOT maintenance district by comparing the annual frequency distribution between the number of days with observed frozen precipitation as identified from the ASOS station data (i.e., snowobserved days) and the number of days with observed snow accumulation [i.e., snow-accumulated days; frozen precipitation accumulation of $0.1 \mathrm{in} .(0.25 \mathrm{~cm})$ or greater] as identified from the GHCN-D site data within $15 \mathrm{~km}$ of an ASOS station (i.e., snow-accumulated days) for each winter season (Fig. 4). An important caveat to note with this approach is that snow reported at a single ASOS station or GHCN-D site within a NDOT district of any duration would be sufficient to count as a snowobserved or snow-accumulated day, respectively.

Statewide, the average number of snow-observed days per winter season was 116.9 days (Fig. 4 and Table 3). This indicates that for the 10 -yr period, on average, somewhere within the state receives snowfall nearly one-third of the year. The annual variability in snowobserved day frequency ranged from 76 days during the 2011/12 winter season to 146 days during the 2009/10 winter season. By this measure, it can be stated that $2009 / 10$ was the most severe winter season in the $10-y r$ 

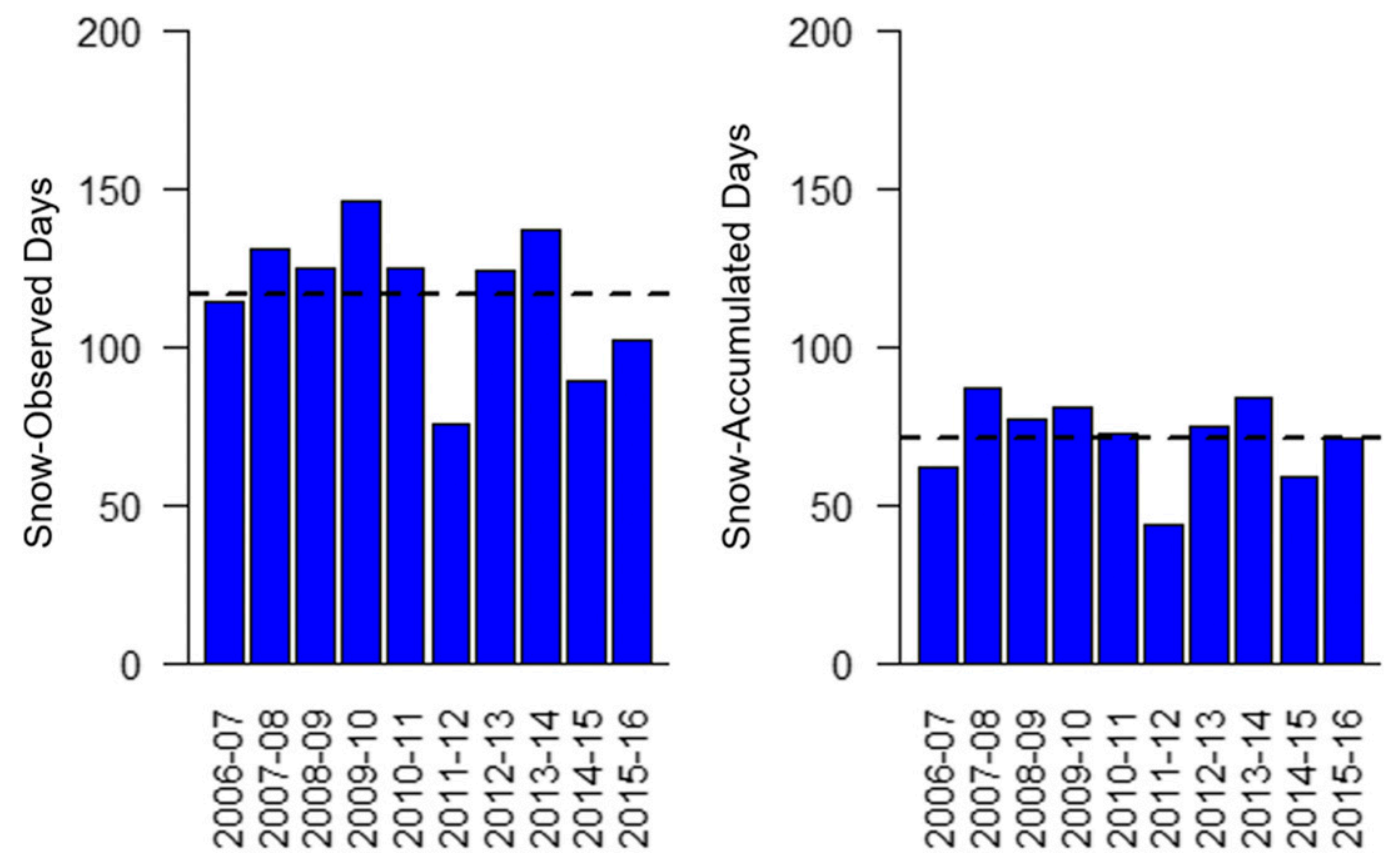

FIG. 4. (left) Snow-observed (i.e., frozen precipitation identified by ASOS stations) days and (right) snowaccumulated (i.e., accumulation measured by GHCN-D sites) days with respective averages (dashed line). Snow-accumulated day frequency is less than that of snow days because precipitating snow may not necessarily accumulate on any given day.

winter season database and 2011/12 was the least severe if only number of days that snow was observed is taken into consideration. At the NDOT maintenance district level, the average snow-observed day frequency ranged from 44.4 days in district 1 (southeast Nebraska) to 74.1 days in district 5 (western Nebraska). Interannual variability in snow-observed day frequency can be seen among the maintenance districts, as well. For example, district 3's highest snow-observed day frequency occurred during the 2012/13 winter season, whereas the statewide highest was the 2009/10 winter season (Table 3). The lowest snow-observed day frequency occurred during the 2011/12 winter season in all districts.
This consistency among the districts confirms that the 2011/12 winter season was a lower frozen precipitation year relative to the others.

Snow-observed day anomalies (i.e., departures from the 10 winter season average; Table 4) were computed statewide and for each district. Statewide, the largest positive snow-observed day anomaly occurred during the 2009/10 winter season, and the largest negative snow-observed day anomaly occurred during the 2011/12 winter season. For the maintenance districts, while the largest negative anomalies were consistent with the 2011/12 winter season, the positive anomalies were more variable. For example, district 1's largest positive

TABLE 3. District and statewide total snow-observed (i.e., frozen precipitation reported by ASOS) days.

\begin{tabular}{lccccccccc}
\hline Winter season & District 1 & District 2 & District 3 & District 4 & District 5 & District 6 & District 7 & District 8 & Statewide \\
\hline $2006 / 07$ & 36 & 40 & 59 & 53 & 67 & 57 & 42 & 67 & 114 \\
$2007 / 08$ & 60 & 61 & 68 & 78 & 86 & 77 & 51 & 67 & 131 \\
$2008 / 09$ & 48 & 55 & 65 & 64 & 71 & 67 & 46 & 75 & 125 \\
$2009 / 10$ & 60 & 70 & 64 & 81 & 84 & 75 & 61 & 67 \\
$2010 / 11$ & 49 & 60 & 63 & 53 & 80 & 61 & 43 & 67 \\
$2011 / 12$ & 28 & 22 & 31 & 35 & 50 & 39 & 27 & 34 \\
$2012 / 13$ & 51 & 58 & 69 & 63 & 77 & 65 & 44 & 66 & 76 \\
$2013 / 14$ & 42 & 59 & 62 & 70 & 94 & 75 & 52 & 77 \\
$2014 / 15$ & 33 & 39 & 42 & 41 & 61 & 48 & 36 & 45 \\
$2015 / 16$ & 37 & 44 & 53 & 44 & 71 & 52 & 43 & 56 \\
Decade average & 44.4 & 50.8 & 57.6 & 58.2 & 74.1 & 61.6 & 44.5 & 62.1 & 137 \\
\hline
\end{tabular}


TABLE 4. District and statewide snow-observed day anomalies. The largest positive anomalies are bold, and the largest negative anomalies are italicized.

\begin{tabular}{crrrrrrrrr}
\hline \hline Winter season & District 1 & District 2 & District 3 & District 4 & District 5 & District 6 & District 7 & District 8 & Statewide \\
\hline $2006 / 07$ & -8.4 & -10.8 & 1.4 & -5.2 & -7.1 & -4.6 & -2.5 & 4.9 & -2.9 \\
$2007 / 08$ & $\mathbf{1 5 . 6}$ & 10.2 & 10.4 & 19.8 & 11.9 & $\mathbf{1 5 . 4}$ & 6.5 & 4.9 & 14.1 \\
$2008 / 09$ & 3.6 & 4.2 & 7.4 & 5.8 & -3.1 & 5.4 & 1.5 & 12.9 \\
$2009 / 10$ & $\mathbf{1 5 . 6}$ & $\mathbf{1 9 . 2}$ & 6.4 & $\mathbf{2 2 . 8}$ & 9.9 & 13.4 & $\mathbf{1 6 . 5}$ & 4.9 & $\mathbf{2 9 . 1}$ \\
$2010 / 11$ & 4.6 & 9.2 & 5.4 & -5.2 & 5.9 & -0.6 & -1.5 & 4.9 & 8.1 \\
$2011 / 12$ & -16.4 & -28.8 & -26.6 & -23.2 & -24.1 & -22.6 & -17.5 & -28.1 \\
$2012 / 13$ & 6.6 & 7.2 & $\mathbf{1 1 . 4}$ & 4.8 & 2.9 & 3.4 & -0.5 & -40.9 \\
$2013 / 14$ & -2.4 & 8.2 & 4.4 & 11.8 & $\mathbf{1 9 . 9}$ & 13.4 & 7.5 & $\mathbf{1 4 . 9}$ & 20.1 \\
$2014 / 15$ & -11.4 & -11.8 & -15.6 & -17.2 & -13.1 & -13.6 & -8.5 & -17.1 & -27.9 \\
$2015 / 16$ & -7.4 & -6.8 & -4.6 & -14.2 & -3.1 & -9.6 & -1.5 & -6.1 & -14.9 \\
\hline
\end{tabular}

snow-observed day anomalies occurred in both the 2007/08 and 2009/10 winter seasons (Table 4). Similarly, district 8's largest positive anomaly occurred during the 2013/14 winter season.

Snow-observed days considered only observed frozen precipitation, whereas snow-accumulated days considered frozen precipitation accumulation. On average, there were 71.3 snow-accumulated days statewide per winter season during the decade (Fig. 4 and Table 5). The statewide range in snow-accumulated day frequency was a minimum of 44 days during the 2011/12 winter season and 87 days during the 2007/08 winter season. By this measure, the 2007/08 winter season was the most severe during the period, while the 2011/12 winter season was the least severe. This difference would suggest that while there was a higher frequency of days with observed snow during the 2009/10 winter season, the snow tended to accumulate on fewer days than in 2007/08. Furthermore, this difference in the most severe winter season between the two methodologies highlights the necessity of a more robust winter severity index that assesses details regarding individual storms. Among the districts, decadal average snow-accumulated day frequency ranged from 22.9 days in district 1 to 47.0 days in district 5 . This result paired with the snow-observed day frequency demonstrates that the eastern part of the state receives on average approximately half the number of snow-observed/snowaccumulated days as the western part of the state. This quantification could be beneficial to NDOT for the purposes of resource planning among the different maintenance districts. Snow-accumulated day anomalies (Table 6) further agree with the 2011/12 winter season as the least severe during the period, with the largest negative anomaly.

The percentage reduction between the number of snowobserved days as the baseline and snow-accumulated days as the reduced metric provides an important statistic for winter maintenance operations (Table 7). NDOT stated that their operations prepare for any forecasted threat of snow and deploy once snow begins (i.e., operations deploy on snow-observed days; NDOT 2016, personal communication). Over the 10-winter-season study period, the statewide average percentage reduction between snow-observed and snow-accumulated days indicates that $39.0 \%$ of the times when it snows, the snow does not result in measurable accumulation. This can be associated with very light snow, snow that melts, or instances of fog incorrectly reported as snow. From discussions with winter maintenance

TABLE 5. District and statewide total snow-accumulated (i.e., accumulation) days.

\begin{tabular}{lccccccccc}
\hline Winter season & District 1 & District 2 & District 3 & District 4 & District 5 & District 6 & District 7 & District 8 & Statewide \\
\hline $2006 / 07$ & 17 & 21 & 21 & 26 & 41 & 26 & 28 & 24 & 62 \\
$2007 / 08$ & 33 & 36 & 43 & 48 & 57 & 35 & 27 & 30 & 87 \\
$2008 / 09$ & 24 & 31 & 43 & 34 & 45 & 31 & 28 & 21 \\
$2009 / 10$ & 32 & 38 & 43 & 45 & 49 & 39 & 31 & 28 \\
$2010 / 11$ & 28 & 37 & 38 & 32 & 51 & 32 & 23 & 38 \\
$2011 / 12$ & 9 & 14 & 15 & 16 & 30 & 20 & 16 & 14 \\
$2012 / 13$ & 21 & 25 & 28 & 37 & 50 & 38 & 28 & 30 & 43 \\
$2013 / 14$ & 24 & 35 & 27 & 37 & 61 & 36 & 25 & 23 \\
$2014 / 15$ & 18 & 22 & 24 & 24 & 44 & 30 & 24 & 21 \\
$2015 / 16$ & 23 & 28 & 31 & 31 & 42 & 35 & 31 & 34 \\
Decade average & 22.9 & 28.7 & 31.3 & 33.0 & 47.0 & 32.2 & 26.1 & 26.2 \\
\hline
\end{tabular}


TABLE 6. District and statewide snow-accumulated day anomalies. The largest positive anomalies are bold, and the largest negative anomalies are italicized.

\begin{tabular}{cccccrrrrr}
\hline \hline Winter season & District 1 & District 2 & District 3 & District 4 & District 5 & District 6 & District 7 & District 8 & Statewide \\
\hline $2006 / 07$ & -5.9 & -7.7 & -10.3 & -7 & -6 & -6.2 & 1.9 & -2.2 & -9.3 \\
$2007 / 08$ & $\mathbf{1 0 . 1}$ & 7.3 & $\mathbf{1 1 . 7}$ & $\mathbf{1 5}$ & 10 & 2.8 & 0.9 & 3.8 & $\mathbf{1 5 . 7}$ \\
$2008 / 09$ & 1.1 & 2.3 & $\mathbf{1 1 . 7}$ & 1 & -2 & -1.2 & 1.9 & -5.2 & 5.7 \\
$2009 / 10$ & 9.1 & $\mathbf{9 . 3}$ & $\mathbf{1 1 . 7}$ & 12 & 2 & $\mathbf{6 . 8}$ & $\mathbf{4 . 9}$ & 1.8 & 9.7 \\
$2010 / 11$ & 5.1 & 8.3 & 6.7 & -1 & 4 & -0.2 & -3.1 & $\mathbf{1 1 . 8}$ & 1.7 \\
$2011 / 12$ & -13.9 & -14.7 & -16.3 & -17 & -17 & -12.2 & -10.1 & -12.2 & -27.3 \\
$2012 / 13$ & -1.9 & -3.7 & -3.3 & 4 & 3 & 5.8 & 1.9 & 3.8 & 3.7 \\
$2013 / 14$ & 1.1 & 6.3 & -4.3 & 4 & $\mathbf{1 4}$ & 3.8 & -1.1 & -3.2 & 12.7 \\
$2014 / 15$ & -4.9 & -6.7 & -7.3 & -9 & -3 & -2.2 & -2.1 & -5.2 & -12.3 \\
$2015 / 16$ & 0.1 & -0.7 & -0.3 & -2 & -5 & 2.8 & $\mathbf{4 . 9}$ & 6.8 & -0.3 \\
\hline
\end{tabular}

operations personnel (Dao et al. 2019), this information could lead to a cost savings in unnecessary deployment expenses; however, even wet snow could require treatment to mitigate subsequent icing. The statewide percentage reduction ranged from $30.4 \%$ during the $2015 / 16$ winter season to $45.6 \%$ during the 2006/07 winter season. At the district level, decadal percentage reductions range from $36.6 \%$ in district 5 to $57.8 \%$ in district 8 . The high variability in these results also highlights the need for a winter severity index that captures individual events during the winter season rather than a frequency distribution of days with snow observed versus accumulated.

One final snow-based index was to investigate the winter seasonal accumulated snowfall (Table 8). The average statewide annual snowfall was $42.6 \mathrm{in}$. $(108.2 \mathrm{~cm})$, with a range from $24.1 \mathrm{in} .(61.2 \mathrm{~cm})$ during the 2011/12 winter season to $60.2 \mathrm{in} .(152.9 \mathrm{~cm})$ during the 2009/10 winter season. This result aligns with the snow-observed day frequency distribution that would suggest that the most severe winter season was 2009/10 and the least severe was 2011/12. The average annual snowfall at the district level ranged from $30.3 \mathrm{in}$. $(76.9 \mathrm{~cm})$ in district 1 to $68.12 \mathrm{in} .(173.0 \mathrm{~cm})$ in district 5 .
This result also aligns with the snow-observed/ snow-accumulated day distribution between the eastern and western regions of the state. Snowfall anomalies (Table 9) illustrate spatial variability using snow-based winter severity indices. Statewide, the largest positive anomaly occurred during the 2009/10 winter season, and the largest negative anomaly occurred during the 2011/12 winter season. At the district level, large negative anomalies were consistent across all eight districts for the 2011/12 winter season. For the 2009/10 winter season, large positive anomalies occurred in all districts except district 8 . While the spatial variability in snow-based indices supports a more robust, event-oriented approach, it also highlights the worthwhile consideration of climate (i.e., temperature and precipitation) anomalies across the state for the 10 -yr period.

\section{b. Climate comparison indices}

To consider a longer, climatology-based index, temperature and precipitation anomalies were obtained from the NOAA NCEI climate division data (ESRL 2017). Because of the lack of a perfect alignment between NCEI climate districts and NDOT maintenance

TABLE 7. District and statewide percent reduction between snow-observed (i.e., precipitation) and snow-accumulated (i.e., accumulation) days.

\begin{tabular}{lccccccccc}
\hline Winter season & District 1 & District 2 & District 3 & District 4 & District 5 & District 6 & District 7 & District 8 & Statewide \\
\hline $2006 / 07$ & 52.8 & 47.5 & 64.4 & 50.9 & 38.8 & 54.4 & 33.3 & 64.2 & 45.6 \\
$2007 / 08$ & 45.0 & 41.0 & 36.8 & 38.5 & 33.7 & 54.5 & 47.1 & 55.2 & 33.6 \\
$2008 / 09$ & 50.0 & 43.6 & 33.8 & 46.9 & 36.6 & 53.7 & 39.1 & 72.0 & 38.4 \\
$2009 / 10$ & 46.7 & 45.7 & 32.8 & 44.4 & 41.7 & 48.0 & 49.2 & 58.2 & 44.5 \\
$2010 / 11$ & 42.9 & 38.3 & 39.7 & 39.6 & 36.3 & 47.5 & 46.5 & 43.3 & 41.6 \\
$2011 / 12$ & 67.9 & 36.4 & 51.6 & 54.3 & 40.0 & 48.7 & 40.7 & 58.8 & 42.1 \\
$2012 / 13$ & 58.8 & 56.9 & 59.4 & 41.3 & 35.1 & 41.5 & 36.4 & 54.5 & 39.5 \\
$2013 / 14$ & 42.9 & 40.7 & 56.5 & 47.1 & 35.1 & 52.0 & 51.9 & 70.1 & 38.7 \\
$2014 / 15$ & 45.5 & 43.6 & 42.9 & 41.5 & 27.9 & 37.5 & 33.3 & 53.3 & 33.7 \\
$2015 / 16$ & 37.8 & 36.4 & 41.5 & 29.5 & 40.8 & 32.7 & 27.9 & 41.1 & 30.4 \\
Decade average & 48.4 & 43.5 & 45.7 & 43.3 & 36.6 & 47.7 & 41.3 & 57.8 & 39.0 \\
\hline
\end{tabular}


TABLE 8. District and statewide total seasonal snowfall accumulation (in.).

\begin{tabular}{lccccccccc}
\hline \hline Winter season & District 1 & District 2 & District 3 & District 4 & District 5 & District 6 & District 7 & District 8 & State average \\
\hline $2006 / 07$ & 36.6 & 37.0 & 32.8 & 26.0 & 61.4 & 46.3 & 47.7 & 31.8 & 40.0 \\
$2007 / 08$ & 36.5 & 30.6 & 46.1 & 43.2 & 75.0 & 38.6 & 42.7 & 42.1 & 44.3 \\
$2008 / 09$ & 23.1 & 32.5 & 46.6 & 40.1 & 57.0 & 40.9 & 40.4 & 41.0 \\
$2009 / 10$ & 57.7 & 63.5 & 63.4 & 66.7 & 87.6 & 60.6 & 49.9 & 31.9 & 40.2 \\
$2010 / 11$ & 38.5 & 51.4 & 54.3 & 53.0 & 66.5 & 53.2 & 41.4 & 59.6 & 52.2 \\
$2011 / 12$ & 15.6 & 28.8 & 21.1 & 24.9 & 31.2 & 23.0 & 30.8 & 17.6 & 24.1 \\
$2012 / 13$ & 27.2 & 40.2 & 37.6 & 47.9 & 74.2 & 51.3 & 53.6 & 52.1 & 48.0 \\
$2013 / 14$ & 21.7 & 22.6 & 24.2 & 33.5 & 82.7 & 40.6 & 36.4 & 32.9 & 36.8 \\
$2014 / 15$ & 22.8 & 22.1 & 26.6 & 33.9 & 69.9 & 27.6 & 25.1 & 30.3 & 32.3 \\
$2015 / 16$ & 23.0 & 34.6 & 59.5 & 42.6 & 75.7 & 47.5 & 49.4 & 51.8 & 48.0 \\
Decade average & 30.3 & 36.3 & 41.2 & 41.2 & 68.1 & 43.0 & 41.7 & 39.1 \\
\hline
\end{tabular}

districts, however, the temperature and precipitation anomalies were accumulated across the eight climate districts to provide a statewide value for each winter season. These anomalies subsequently were compared with the aforementioned snow-based winter severity indices and the final NEWINS.

For a climate-based index, precipitation and temperature anomalies were obtained from the eight climate districts within the state of Nebraska from October through April of each winter season and averaged statewide (Table 10). For severity purposes, the anomalies are ranked, with larger positive precipitation anomalies (i.e., more possible frozen precipitation) and larger negative temperature anomalies (i.e., colder winter) associated with a higher winter severity. For precipitation anomalies, the largest positive anomaly ( 4.30 in.; $10.92 \mathrm{~cm}$ ) occurred during the 2015/16 winter season, while the largest negatively anomaly occurred during the 2014/15 winter season (-2.02 in.; $-5.13 \mathrm{~cm})$. From the snowfall data, the most severe 2009/10 winter season ranked third in the precipitation anomalies and the least severe 2011/12 winter season ranked sixth in precipitation anomalies. These results provide stark contrast to the snow-based indices. However, while the 2015/16 winter season may have included an abundance of precipitation, it was not in the form of snow. For temperature anomalies, the largest negative anomaly occurred during the $2013 / 14$ winter season $\left(-1.46^{\circ} \mathrm{F}\right.$; $-0.81^{\circ} \mathrm{C}$ ), while the largest positively anomaly occurred during the $2011 / 12$ winter season $\left(5.18^{\circ} \mathrm{F} ; 2.88^{\circ} \mathrm{C}\right)$. This result agrees with the previous ranking of the 2011/12 winter season as the least severe season from the snowfall data. The 2009/10 winter season ranks second-lowest in the temperature anomalies $\left(-1.21^{\circ} \mathrm{F}\right.$; $-0.67^{\circ} \mathrm{C}$ ), which is more in agreement with the snowbased index. Given the misalignment between climate districts and maintenance districts, it was not feasible to conduct a district-level anomaly comparison. The snowfall and climate-based indices support the use of a hybrid approach that considers snowfall and temperature, in addition to other weather variables at the level of individual events.

\section{c. NEWINS}

The first component of the NEWINS produced a categorical (Fig. 2) frequency distribution of classified events statewide (Fig. 5 and Table 11) and at the district level (not shown) for each of the 10 winter seasons within the study period. Statewide, the average number of events was 246.7 (Table 11). The 2011/12 winter

TABLE 9. District and statewide snowfall accumulation anomalies (in.). The largest positive anomalies are bold, and the largest negative anomalies are italicized.

\begin{tabular}{crrrrrrrrr}
\hline \hline Winter season & District 1 & District 2 & District 3 & District 4 & District 5 & District 6 & District 7 & District 8 & State average \\
\hline $2006 / 07$ & 6.3 & 0.7 & -8.4 & -15.2 & -6.7 & 3.3 & 5.9 & -7.3 & -2.6 \\
$2007 / 08$ & 6.2 & -5.7 & 4.9 & 2.0 & 6.9 & -4.4 & 0.9 & 3.0 & 1.7 \\
$2008 / 09$ & -7.2 & -3.8 & 5.4 & -1.1 & -11.1 & -2.0 & -1.3 & 1.9 & -2.4 \\
$2009 / 10$ & $\mathbf{2 7 . 4}$ & $\mathbf{2 7 . 2}$ & $\mathbf{2 2 . 2}$ & $\mathbf{2 5 . 5}$ & $\mathbf{1 9 . 5}$ & $\mathbf{1 7 . 6}$ & 8.1 & -7.2 & $\mathbf{1 7 . 6}$ \\
$2010 / 11$ & 8.2 & 15.1 & 13.1 & 11.8 & -1.6 & 10.2 & -0.4 & $\mathbf{2 0 . 5}$ & 9.6 \\
$2011 / 12$ & -14.7 & -7.5 & -20.1 & -16.3 & -36.9 & -20.0 & -10.9 & -21.5 & -18.5 \\
$2012 / 13$ & -3.1 & 3.9 & -3.6 & 6.7 & 6.1 & 8.3 & $\mathbf{1 1 . 9}$ & 13.0 & 5.4 \\
$2013 / 14$ & -8.6 & -13.7 & -17.0 & -7.7 & 14.6 & -2.4 & -5.4 & -6.2 & -5.8 \\
$2014 / 15$ & -7.5 & -14.2 & -14.6 & -7.3 & 1.8 & -15.4 & -16.7 & -8.8 & -10.3 \\
$2015 / 16$ & -7.3 & -1.7 & 18.3 & 1.4 & 7.6 & 4.5 & 7.7 & 12.7 & 5.4 \\
\hline
\end{tabular}


TABLE 10. Average statewide decadal temperature and precipitation anomalies. The largest positive anomalies are bold, and the largest negative anomalies are italicized.

\begin{tabular}{ccccc}
\hline \hline Winter season & Precipitation anomaly (in.) & Precipitation anomaly rank & Temperature anomaly $\left({ }^{\circ}\right.$ F) & Temperature anomaly rank \\
\hline $2006 / 07$ & 2.84 & 2 & 0.68 & 7 \\
$2007 / 08$ & 0.74 & 5 & -0.58 & 3 \\
$2008 / 09$ & 1.97 & 4 & 0.43 & 6 \\
$2009 / 10$ & 2.71 & 3 & -1.21 & 2 \\
$2010 / 11$ & -1.57 & 9 & -0.23 & 4 \\
$2011 / 12$ & -0.10 & 6 & -0.16 & 5 \\
$2012 / 13$ & -1.52 & 8 & -1.46 & 1 \\
$2013 / 14$ & -1.34 & 7 & 1.66 & 8 \\
$2014 / 15$ & -2.02 & 10 & 4.57 & 9 \\
$2015 / 16$ & $\mathbf{4 . 3 0}$ & 1 & & \\
\hline
\end{tabular}

season had the fewest events, at 134, and the 2007/08 and 2009/10 winter seasons were tied for the most events, with 305 . Trace (i.e., category 1 ) events were the most frequent, while high (i.e., category 6) events were rare, with several winter seasons observing none (Table 11). Slight (i.e., category 3 ) and enhanced (i.e., category 4) events exhibited more variability in their frequency distributions. Given the categorical assignment (Fig. 2) and Eq. (1), the middle events are likely to overlap with one another, as subtle changes could alter their classification. The extreme events (i.e., trace and high) are more distinct from one another and therefore do not exhibit any degree of overlap or similarity. Moreover, the sample size of category 6 events is very limited compared to category 1. These are important caveats to note in both the frequency distribution and eventual final NEWINS seasonal values.

The final NEWINS was computed via Eq. (2) to provide a single value for each winter season statewide and at the NDOT maintenance district level (Fig. 6 and Table 12). The statewide decadal average NEWINS value was 4.77. Based on the NEWINS values, the least severe winter season was 2011/12, with a value of 2.49 , while the most severe winter season was 2009/10, with a value of 6.33 (Fig. 6 and Table 12). These results generally align with the snow-based winter severity indices. At the district level, the NEWINS value summed across all districts would yield the statewide value. District 1 (southeast Nebraska) has the smallest contribution on average for the decade (0.44), while district 5 (western Nebraska) has the largest contribution for the decade (0.90) of any one single district (Table 12). This result is supported by climatology, given the relative differences in event frequency and snow-observed/snow-accumulated days between the eastern and western parts of the state. A more detailed consideration of the district-level NEWINS values also revealed that, while the 2009/10 winter season was the most severe for the entire state, individual districts' most severe winter seasons were variable. For example, district 8's most severe was the 2010/11 winter season with an NEWINS value of 0.83 (Table 12). Corresponding differences between districts were observed in the snow-based winter severity indices, and it is important that the NEWINS also be able to capture the same level of variability to be reliable. Moreover, this result highlights the challenge and difficulty of representing an entire state's winter season with a single severity index value.

The advantages of the NEWINS become more apparent when the NEWINS anomalies (Fig. 7) are compared with the snow-based and climate-based index anomalies ranked from most severe to least severe for each respective index (Tables 13 and 14). For the snow-based anomalies (i.e., snowfall amounts, snowobserved days, and snow-accumulated days), there is good agreement that the 2011/12 winter season was the least severe in the decade and the 2009/10 winter season was the most severe in the decade. The exception is that for the snow-accumulated days anomaly, the 2009/10 winter season is ranked as the third most severe winter season. There is also fair agreement between the cutoff threshold between positive (i.e., more severe) and negative (i.e., less severe) anomalies for each winter season. The exception to this is with the snowfall anomalies, particularly during the 2015/16 winter season, which did have a positive snowfall anomaly (ranked third most severe) but average (i.e., zero anomaly) NEWINS, snow-observed day, and snow-accumulated day anomalies (ranked seventh or eighth most severe).

As suggested from the frequency distributions, while there is agreement in the least and most severe winter seasons between the NEWINS and snow-based anomalies, the greatest variability is in the middle, where subtle differences in the variables of interest can influence the rank of the winter seasons. While the 

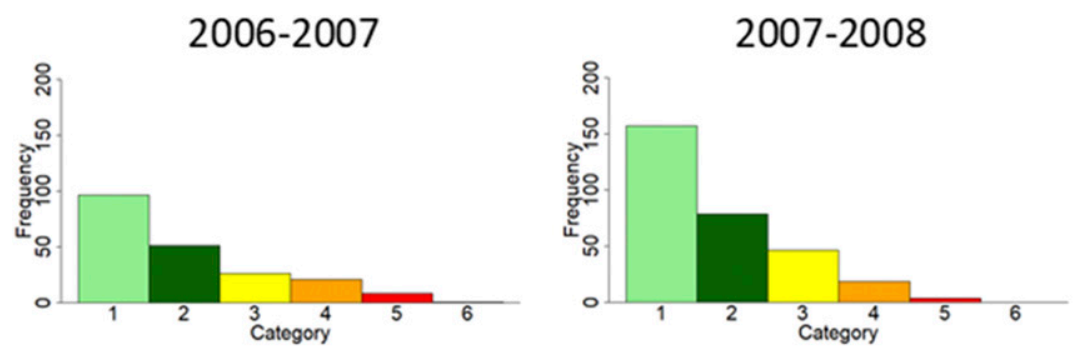

$2009-2010$
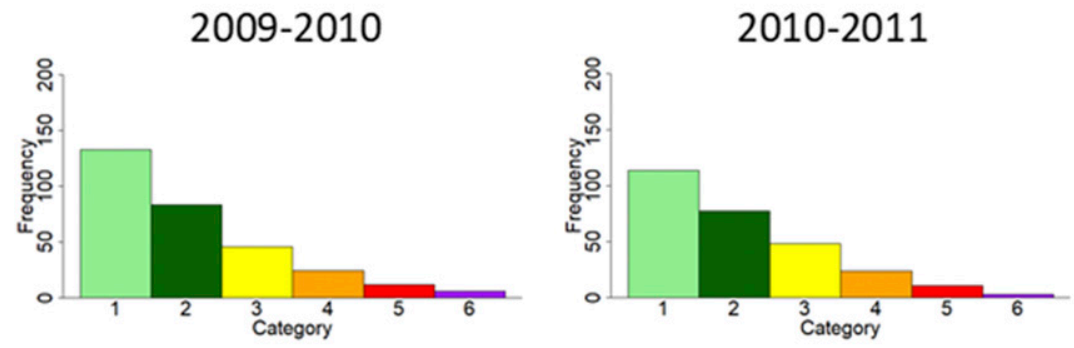

$2012-2013$
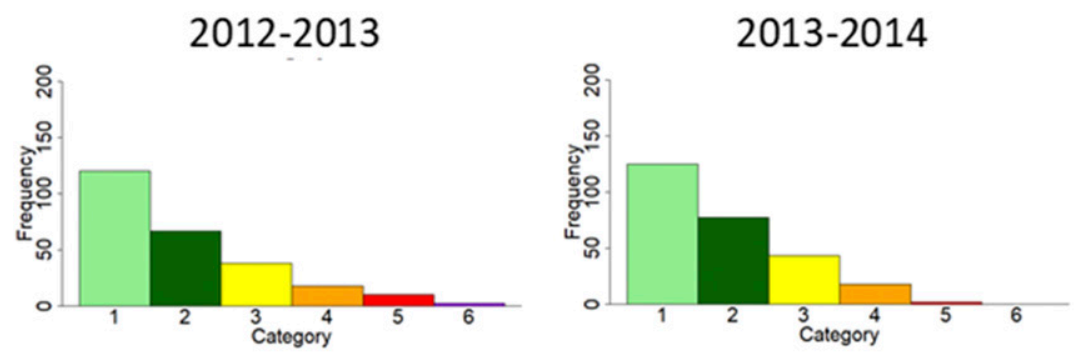
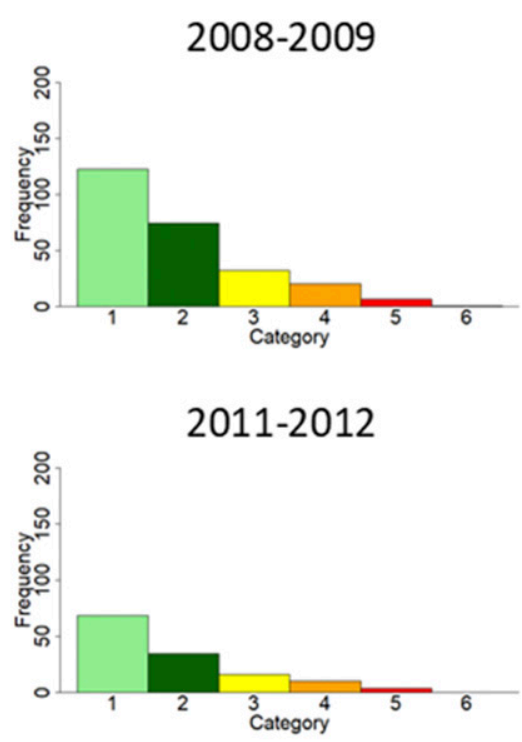

2011-2012

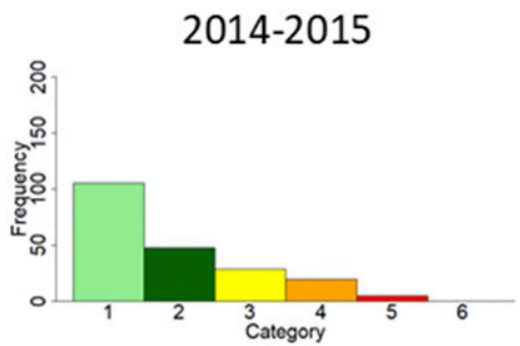

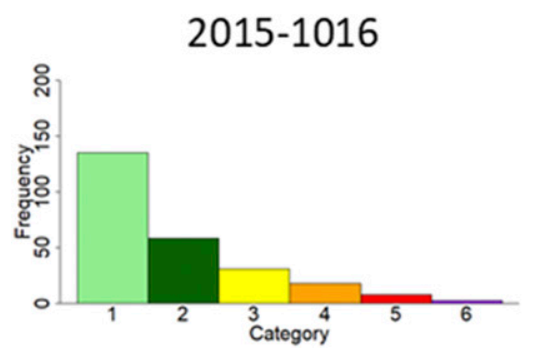

FIG. 5. NEWINS winter-season categorical event distribution.

NEWINS and snow-based anomalies both exhibit this intermediate variability, one advantage is that the NEWINS considers additional variables (Fig. 3) and not simply event frequency or snowfall amounts exclusively. For the climate-based index anomalies (Table 14), temperature anomalies also exhibited a clear cutoff between negative (i.e., more severe in the case of temperature) and positive (i.e., less severe in the case of temperature) anomalies for the corresponding NEWINS anomalies. The precipitation anomalies, though, did not exhibit any clear pattern that was similar to observed NEWINS or snowfall anomalies. A reason for this is that precipitation anomalies consider both liquid and frozen precipitation; however, the
NEWINS and other approaches include only frozen precipitation. A "wet" or "dry" winter season from the climatological precipitation standpoint can be very different than a "snowy" winter.

\section{d. NEWINS 2015/16 winter season maintenance performance comparison}

NDOT's performance objective for its winter maintenance operations is to maintain traffic speeds along the Interstate 80 corridor at or above $65 \mathrm{mph}\left(29.1 \mathrm{~m} \mathrm{~s}^{-1}\right)$ for both directions (i.e., eastbound and westbound) within six hours of the precipitation ending (NDOT 2016, personal communication). The 2015/16 winter season NDOT performance data were available for 15 events 
TABLE 11. Statewide categorical event classification frequency distribution.

\begin{tabular}{|c|c|c|c|c|c|c|c|}
\hline Winter season & Trace (1) & Marginal (2) & Slight (3) & Enhanced (4) & Moderate (5) & High (6) & Total \\
\hline $2006 / 07$ & 98 & 51 & 21 & 23 & 10 & 1 & 204 \\
\hline $2007 / 08$ & 155 & 85 & 41 & 22 & 2 & 0 & 305 \\
\hline 2008/09 & 123 & 88 & 22 & 18 & 6 & 0 & 257 \\
\hline $2009 / 10$ & 129 & 96 & 39 & 25 & 13 & 3 & 305 \\
\hline $2010 / 11$ & 114 & 92 & 37 & 23 & 11 & 1 & 278 \\
\hline $2011 / 12$ & 65 & 35 & 15 & 12 & 7 & 0 & 134 \\
\hline $2012 / 13$ & 113 & 74 & 35 & 21 & 13 & 0 & 256 \\
\hline $2013 / 14$ & 136 & 80 & 36 & 13 & 2 & 0 & 267 \\
\hline $2014 / 15$ & 112 & 54 & 19 & 20 & 2 & 0 & 207 \\
\hline 2015/16 & 127 & 67 & 24 & 22 & 12 & 2 & 254 \\
\hline Decade average & 117.2 & 72.2 & 28.9 & 19.9 & 7.8 & 0.7 & 246.7 \\
\hline
\end{tabular}

throughout the state (Table 15). Of these 15 events, seven resulted in the performance objective not being met. Reasons for the performance objective not being met range from severe weather conditions to vehicular crashes and necessary road closures. The performance data for the 2015/16 winter season was related to the individual NEWINS storm classifications for each of the Interstate 80 districts (Table 15). The results show that, in general, the performance objective was met in $81.3 \%$ of lower impact category 1-3 events (e.g., 16 November 2015,16 January 2016) but only in $12.5 \%$ of higher impact category 4-6 events (e.g., 15 December 2015, 1 February 2016). Some important caveats were identified in this comparison analysis. First, NDOT's event definition is based on precipitation that causes a maintenance response (e.g., wet snow, freezing rain, potential for icy roads) regardless of the final snowfall accumulation (NDOT 2016, personal communication). Given that the NEWINS only considers events with accumulated snowfall, this results in events included in NDOT's maintenance database that are missing from the NEWINS database (e.g., "NA" on 16 November 2015; Table 15). Future alignment of event definitions is necessary to improve the usefulness of the NEWINS. An additional caveat is that in some of the lower-impact events, performance was affected by weather and closures outside of Nebraska resulting in poor performance (e.g., 26 November 2015, district 5). Upon discussion with NDOT, it was revealed that this was due to the Wyoming DOT closing its roads because of significantly worse weather conditions, creating a backup of traffic into Nebraska (NDOT 2016, personal communication). This is an important consideration as the NEWINS is a pure meteorological index and does not consider transportation-related incidents (e.g., road closures, highway crashes). Overall, higher impact/severity storms were associated with more numerous instances of road closures.

\section{e. NEWINS limitations and extensions}

The NEWINS was intended to suit NDOT needs and provide a flexible framework for other transportation agencies and end users, as well. It is important to consider NEWINS limitations in addition to possible extensions of this framework. The categorical frequency distribution and event classification component of the NEWINS builds on the framework in the development of the Northeast snowfall impact scale (NESIS; Kocin and Uccellini 2004) and LWSS (Cerruti and Decker 2011). Cerruti and Decker (2011) observed a similar distribution with higher category (i.e., impact) events exhibiting far lower frequencies relative to lower category events. Also, while the parameter weights differed between the NEWINS and LWSS, both approaches gave the most weight to the snowfall amount parameter. As noted, freezing rain data lacked availability through the 10-yr study period and were omitted during the development of the NEWINS, unlike the LWSS, which considered freezing rain events. Future refinement of the NEWINS could ensure freezing rain is incorporated into the WSI. These additional improvements also could make the NEWINS framework useful for decision-makers in conjunction with the NWS WSSI (WPC 2018).

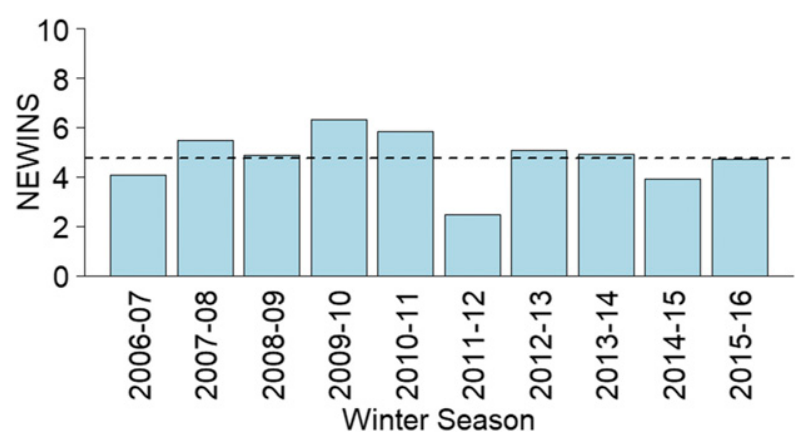

FIG. 6. NEWINS winter-season values with decadal average (black dashed line). 
TABLE 12. NEWINS district and statewide seasonal values.

\begin{tabular}{lccccccccc}
\hline \hline Winter season & District 1 & District 2 & District 3 & District 4 & District 5 & District 6 & District 7 & District 8 & Statewide \\
\hline $2006 / 07$ & 0.44 & 0.46 & 0.43 & 0.43 & 0.74 & 0.56 & 0.58 & 0.43 \\
$2007 / 08$ & 0.59 & 0.58 & 0.79 & 0.72 & 1.02 & 0.58 & 0.60 & 0.60 & 5.08 \\
$2008 / 09$ & 0.41 & 0.53 & 0.78 & 0.63 & 0.84 & 0.58 & 0.56 & 0.54 & 4.87 \\
$2009 / 10$ & 0.69 & 0.81 & 0.88 & 0.88 & 1.11 & 0.76 & 0.66 & 0.53 & 6.33 \\
$2010 / 11$ & 0.56 & 0.75 & 0.79 & 0.69 & 0.98 & 0.70 & 0.55 & 0.83 \\
$2011 / 12$ & 0.19 & 0.33 & 0.29 & 0.30 & 0.46 & 0.32 & 0.35 & 0.24 \\
$2012 / 13$ & 0.38 & 0.48 & 0.52 & 0.68 & 1.00 & 0.71 & 0.65 & 0.65 \\
$2013 / 14$ & 0.42 & 0.54 & 0.46 & 0.63 & 1.15 & 0.66 & 0.55 & 0.51 \\
$2014 / 15$ & 0.36 & 0.38 & 0.46 & 0.49 & 0.88 & 0.49 & 0.42 & 0.45 \\
$2015 / 16$ & 0.38 & 0.51 & 0.66 & 0.55 & 0.84 & 0.60 & 0.55 & 0.66 & 3.93 \\
Decade average & 0.44 & 0.54 & 0.61 & 0.60 & 0.90 & 0.60 & 0.55 & 0.54 & 4.73 \\
\hline
\end{tabular}

From a meteorological perspective, an important limitation of the NEWINS categorical parameter assignment (Fig. 3) is that these thresholds were tailored to winter maintenance operations through an iterative process. Air temperature thresholds did not cut off at the observed $10-\mathrm{m}$ temperature reaching $0^{\circ} \mathrm{C}$, because road icing can occur above or below this threshold, particularly for elevated road surfaces. Additionally, chemical treatments around the meteorological freezing point are similar and do not change until temperatures are colder (NDOT 2016, personal communication). Derived parameters, such as snowfall rate (snow amount divided by duration), represent another important limitation; such parameters provide only a rough approximation, as actual rates can vary significantly during the period of snowfall. Further, the spatial averaging of parameters such as visibility would not provide a useful approximation of snowfall rate, since the period of time for averaging is when snowfall is occurring and not an instantaneous observation. For additional consideration of the impact of the spatial averaging over the period of snowfall, in the 2009/10 winter season (most severe by several discussed metrics) there are only three instances of a category 6 storm compared to 13 instances of a category 5 storm. In those category 6 instances, the corresponding visibilities ranged from 0.95 to $1.25 \mathrm{mi}$ over durations ranging from 16 to $20 \mathrm{~h}$, which would place the visibilities in category 6 , as well. However, in the category 5 instances, visibilities ranged from 0.93 to $9.55 \mathrm{mi}$ which would not place all of them within category 5 based on visibility alone. For the entire 2009/10 winter season event database containing 305 events, the lowest observed visibility for any event was $0.48 \mathrm{mi}$, and this particular event ultimately received a storm classification of category 2 because of the influence of the remaining parameters and their respective weights. Spatially, the threshold between ASOS stations and GHCN-D sites likely would require modification in regions with complex terrain and in situations with localized mesoscale snowbands (e.g., lake effect). One final important limitation of the NEWINS is that, while its 10-winter season development was longer than most of its counterparts, a longer period would be more desirable for meteorological and climatological context. The 10 winter seasons selected were determined in consultation with NDOT.

In terms of transportation-related considerations, road pavement temperature would be ideal for future inclusion among the parameters; however, Walker and Anderson (2016) had previously demonstrated numerous quality control issues with these data. Transportation agencies would benefit from increasing resources for their instrumentation to be used in products such as the NEWINS. In its current form, the NEWINS was intended to provide a meteorological quantification of winter storm and seasonal severity; however, future consideration of relevant nonmeteorological data such as traffic volumes, time of day, day of the week, and population would be prudent. While the NESIS (Kocin and Uccellini 2004) considers population, the impact of winter storms would be underrepresented for states like Nebraska with sparsely populated areas. Furthermore, these nonmeteorological variables and other event considerations (e.g., freezing rain, blowing/drifting snow, frost) would be

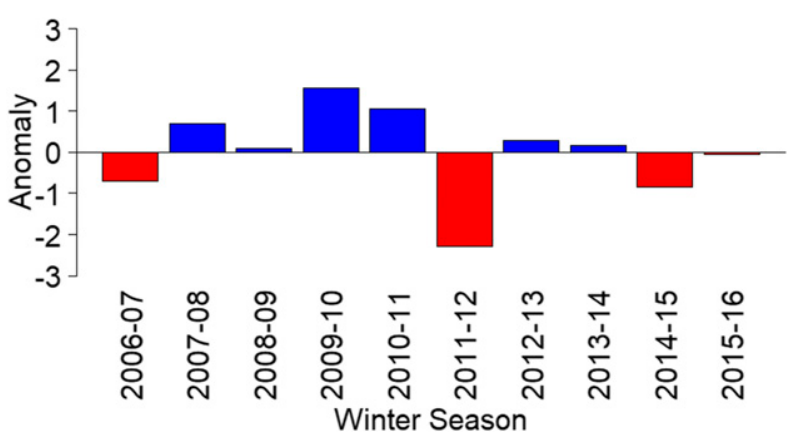

FIG. 7. NEWINS winter-season anomalies with positive (blue) and negative (red). 
important to better align the NEWINS with winter maintenance operations costs. Nevertheless, the NEWINS is a useful tool with substantial opportunities for future expansion and refinement in conjunction with other products in development.

\section{Summary and conclusions}

The winter severity index developed specifically for NDOT is known as the NEWINS. The NEWINS serves an integral role in providing a description of winter in the context of transportation requirements through an independent, meteorological baseline for 10 winter seasons beginning in July 2006 for the state of Nebraska. Through the development of the NEWINS, a winter event categorical classification framework was developed. This classification framework allowed for a weighted linear combination of seven key weather variables to create a frequency distribution of events for each winter season. This frequency distribution ultimately resulted in the final seasonal NEWINS value. The NEWINS values were also compared alongside snow-based and climate-based index approaches.

Consideration of the annual distribution of days with observed snowfall (i.e., snow-observed days) versus days with observed snowfall accumulation (i.e., snowaccumulated days) revealed an average of $39 \%$ fewer snow-accumulated than snow-observed days for the 10 -yr period. These results also revealed that the western part of Nebraska receives twice as many days with snowfall compared to the eastern part of the state, as well as more than twice the amount of snowfall as the eastern part. A consideration of snow-observed day, snow-accumulated day, and snowfall amount anomalies underscore the spatial and temporal variability that the NEWINS must consider. The snow data (i.e., days and amount) suggest the 2011/12 winter season was the least severe and the 2009/10 winter season was the most severe.

Climatological liquid-equivalent precipitation and temperature anomalies provided an additional context for the NEWINS results. Liquid-equivalent precipitation anomalies were not well aligned with the snow anomalies and NEWINS results, likely because of the combination of both rain and snow events in precipitation data. The temperature anomalies showed better alignment with the snow data and NEWINS results, including a clear separation between positive and negative anomalies when compared to different winter season severities.

The NEWINS results highlight the 2011/12 winter season as the least severe and the 2009/10 winter season as the most severe during the study period. These two 


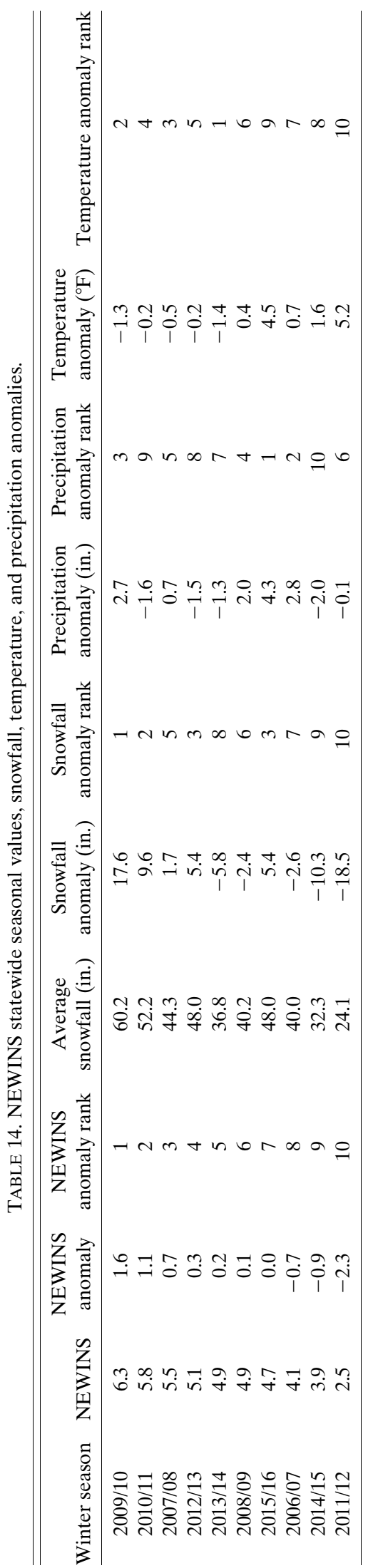

winter seasons were also identified similarly by the other index measures. The NEWINS also captures the spatial differences in winter severity, especially between eastern and western regions of Nebraska. More substantial differences and inconsistency arose between the NEWINS and other (i.e., snow-based and climate-based) index approaches during the intermediate winter seasons, in which subtle differences could alter a particular season's ranking.

The overall strengths of the NEWINS are that it 1) considers a wide range of surface, ASOS-based meteorological variables; 2 ) incorporates a categorical frequency distribution framework related to weather impacts on road conditions and winter maintenance operations; 3 ) is robust and flexible enough to be computed at the statewide and district levels; 4) can be modified to include additional parameters such as freezing rain and road temperature; and 5) can be correlated to available transportation data (e.g., traffic speeds, winter maintenance operations costs) once available. Additionally, the NEWINS independently and explicitly considers the individual contribution of select meteorological parameters spatiotemporally during events, and the combined influence of these parameters yield a storm classification frequency distribution that is accumulated throughout a winter season. The NEWINS provides a finer resolution than most existing WSIs by considering storm-level data. Furthermore, the NEWINS focuses on meteorological conditions and can subsequently be compared independently with transportation and winter maintenance data.

The benefits of the NEWINS are that it allows NDOT to assess the performance of its winter maintenance operations activities, resource allocations, and other expenses with respect to the severity, or magnitude, of each winter season. NDOT's goal is to efficiently maintain safety and mobility for the public and commercial transportation interests. This information can be used to increase efficiency in resource allocation and maintenance operations, in addition to the identification of conditions that would prompt the need for increases or reductions in assets. The NEWINS considers multiple weather variables across spatiotemporal scales to provide the best resolution of true winter severity in a framework that can be tailored to the end-user needs. Moreover, it is flexible and robust enough to be transferred to other regions and applications (e.g., modification of variables and weight sensitivity for different industries such as agriculture and renewable energy).

Future work includes expansion of the NEWINS framework to multiple states and adding a predictive value so that it can be used as a planning tool in addition to a post-winter-season assessment. To this end, 
TABLE 15. Interstate 80 corridor district-level 2015-16 winter maintenance performance evaluation. NDOT's event criterion (i.e., storm dates) was precipitation that resulted in maintenance activity (NDOT 2016, personal communication). The numbers within the boxes represent the 2015-16 winter season NEWINS storm classification and "NA" denotes the storm failed NEWINS criteria. This could be due to several reasons; for example, lack of accumulation (i.e., snow days vs snowfall days), snow melted before observation time, or freezing rain events that were omitted from the NEWINS.

\begin{tabular}{lccccc}
\hline \hline & District & District & District & District & District \\
Storm date & 5 & 6 & 4 & 1 & 2 \\
\hline 10 Nov 2015 & 2 & - & - & - & - \\
16 Nov 2015 & 1 & 1 & NA & NA & NA \\
17 Nov 2015 & - & - & - & NA & - \\
26 Nov 2015 & $1^{\mathrm{a}}$ & NA & 2 & NA & 1 \\
29 Nov 2015 & - & 2 & - & - & 3 \\
1 Dec 2015 & - & - & 1 & - & - \\
12 Dec 2015 & $2^{\mathrm{a}}$ & 1 & 1 & 1 & 2 \\
15 Dec 2015 & $6^{\mathrm{a}}$ & $4^{\mathrm{a}}$ & $2^{\mathrm{a}}$ & - & - \\
22 Dec 2015 & $\mathrm{NA}^{\mathrm{a}}$ & 1 & - & 2 & 1 \\
25 Dec 2015 & $5^{\mathrm{a}}$ & $2^{\mathrm{a}}$ & 1 & 3 & 4 \\
29 Dec 2015 & - & - & 1 & 1 & 1 \\
7 Jan 2016 & - & - & $2^{\mathrm{a}}$ & 1 & 2 \\
16 Jan 2016 & 1 & & 1 & - & - \\
18 Jan 2016 & - & - & - & 1 & 2 \\
1 Feb 2016 & $4^{\mathrm{a}}$ & $5^{\mathrm{a}}$ & $5^{\mathrm{a}}$ & $3^{\mathrm{a}}$ & $4^{\mathrm{a}}$ \\
\hline
\end{tabular}

${ }^{a}$ Denotes an event where the NDOT performance objective was not met.

machine and deep learning algorithms may leverage the categorical frequency distribution component of the NEWINS. Additional research prospects include direct correlation between the NEWINS and more robust winter maintenance operations data, such as salt usage, personnel hours, lane miles plowed, crash data, or costs. The versatility of the NEWINS provides an asset to the meteorology and transportation communities.

Acknowledgments. Much of the material in this paper is from the dissertation of the lead author (Walker 2018), provided for the convenience of the reader. The study described in this paper was sponsored and supported by the National Science Foundation Graduate Research Fellowship under Grant DGE-1041000, Nebraska Department of Transportation Project Grant SPR-P1(17) M054, and the Advanced Study Program at the National Center for Atmospheric Research. The National Center for Atmospheric Research is sponsored by the National Science Foundation. Any opinions, findings, and conclusions or recommendations expressed in this material are those of the writers and do not necessarily reflect the views of the National Science Foundation, University of Nebraska, Nebraska Department of Transportation, or National Center for Atmospheric Research.
The authors wish to acknowledge and thank the contributions of Nebraska Department of Transportation staff, especially Tom Sands, Austin Yates, Todd Cecrle, and Jesse Schulz, for providing significant inputs to complete this study. Additionally, the authors wish to thank Sue Ellen Haupt, Amanda Siems-Anderson, William "Bill" Mahoney, and Julie Demuth for their comments on the manuscript. Last, the authors wish to thank the anonymous reviewers and editors for their contributions to strengthen the manuscript.

\section{REFERENCES}

Black, A. W., and T. L. Mote, 2015a: Characteristics of winterprecipitation-related transportation fatalities in the United States. Wea. Climate Soc., 7, 133-145, https://doi.org/10.1175/ WCAS-D-14-00011.1.

$\longrightarrow$, and,$- 2015 \mathrm{~b}$ : Effects of winter precipitation on automobile collisions, injuries, and fatalities in the United States. J. Transp. Geogr., 48, 165-175, https://doi.org/10.1016/j.jtrangeo.2015.09.007.

Blincoe, L. J., T. R. Miller, E. Zaloshnja, and B. A. Lawrence, 2015: The economic and societal impact of motor vehicle crashes, 2010. National Highway Traffic Safety Administration Rep. DOT HS 812 013, 304 pp.

Boselly, S. E., J. E. Thornes, and C. Ulberg, 1993: Road Weather Information Systems Volume 1: Research Report. National Research Council Rep. SHRP-H-350, 219 pp.

Boustead, B., S. D. Hilberg, M. D. Shulski, and K. G. Hubbard, 2015: The Accumulated Winter Season Severity Index (AWSSI). J. Appl. Meteor. Climatol., 54, 1693-1712, https://doi.org/10.1175/ JAMC-D-14-0217.1.

Call, D. A., 2011: The effect of snow on traffic counts in western New York State. Wea. Climate Soc., 3, 71-75, https://doi.org/ 10.1175/WCAS-D-10-05008.1.

Carmichael, C. G., W. A. Gallus Jr., B. R. Temeyer, and M. K. Bryden, 2004: A winter weather index for estimating winter roadway maintenance costs in the Midwest. J. Appl. Meteor., 43, 1783-1790, https://doi.org/10.1175/JAM2167.1.

Cerruti, B. J., and S. G. Decker, 2011: The Local Winter Storm Scale: A measure of the intrinsic ability of winter storms to disrupt society. Bull. Amer. Meteor. Soc., 92, 721-737, https://doi.org/10.1175/ 2010BAMS3191.1.

Changnon, S. A., and T. G. Creech, 2003: Sources of data on freezing rain and resulting damages. J. Appl. Meteor., 42, 1514-1518, https:// doi.org/10.1175/1520-0450(2003)042<1514:SODOFR >2.0.CO;2.

CPC, 2018: Nebraska climate divisions. NCEP, accessed 19 March 2018, http://www.cpc.ncep.noaa.gov/products/analysis_ monitoring/regional_monitoring/CLIM_DIVS/nebraska.gif.

CoCoRaHS, 2018: Welcome to CoCoRaHS! Accessed 15 January 2018, https://www.cocorahs.org/.

Cohen, S. J., 1981: User oriented climatic information for planning a snow removal budget. J. Appl. Meteor., 20, 1420-1427, https:// doi.org/10.1175/1520-0450(1981)020<1420:UOCIFP > 2.0.CO;2.

Dao, B., S. Hasanzadeh, C. L. Walker, D. Steinkruger, B. Esmaeili, and M. R. Anderson, 2019: Current practices of winter maintenance operations and perceptions of winter weather conditions. J. Cold Reg. Eng., 33, https://doi.org/10.1061/ (ASCE)CR.1943-5495.0000191.

ESRL, 2017: Location of US climate divisions. NOAA, accessed 1 January 2017, https:/www.esrl.noaa.gov/psd/data/usclimdivs/ data/map.html\#Nebraska\%20. 
Jensen, D., B. Koeberlein, E. Bala, and P. Bridge, 2013: Development of winter maintenance performance measures. Idaho Transportation Department, 6 pp.

Jiusto, J. E., and H. K. Weickmann, 1973: Types of snowfall. Bull. Amer. Meteor. Soc., 54, 1148-1162, https://doi.org/10.1175/ 1520-0477(1973)054<1148:TOS>2.0.CO;2.

Kipp, W., and D. Sanborn, 2013: Identifying performance based measures for winter maintenance practices. Vermont Agency of Transportation Rep. 2013-02, 15 pp.

Kocin, P. J., and L. W. Uccellini, 2004: A snowfall impact scale derived from Northeast storm snowfall distributions. Bull. Amer. Meteor. Soc., 85, 177-194, https://doi.org/10.1175/BAMS-85-2-177.

Mahoney, J., E. Jackson, D. Larsen, T. Vadas, K. Wille, and S. Zinke, 2015: Winter Highway Maintenance Operations: Connecticut. Connecticut Academy of Science and Engineering Rep. CT-2289-F-15-1, 248 pp.

MNDNR, 2018: Deer reports \& statistics. Accessed 18 March 2018, https:/www.dnr.state.mn.us/mammals/deer/management/ statistics.html.

MRCC, 2018: Research: Accumulated winter season severity index (AWSSI). Accessed on 11 March 2018, http://mrcc.isws.illinois.edu/ research/awssi/indexAwssi.jsp.

NCEI, 2017a: Land-based stations: Automated Surface Observing System station, surface data hourly global (DS3505). Subset used: July 2006-June 2016, NOAA, accessed 1 January 2017, https://www7.ncdc.noaa.gov/CDO/ cdoselect.cmd.

__ 2017b: Global Historical Climatology Network-Daily. Subset used: July 2006-June 2016, NOAA, accessed 1 January 2017, https://www.ncdc.noaa.gov/cdo-web/search.

NeRAIN, 2018: Welcome to the Nebraska Rainfall Assessment and Information Network. Accessed 15 January 2018, https:// nednr.nebraska.gov/nerain.

NHTSA, 2018: New NHTSA study shows motor vehicle crashes have $\$ 871$ billion economic and societal impact on U.S. citizens. Accessed 10 March 2018, https://www.nhtsa.gov/press-releases/ new-nhtsa-study-shows-motor-vehicle-crashes-have-871-billioneconomic-and-societal.

Nixon, W., and L. Qiu, 2005: Developing a storm severity index. Transp. Res. Rec., 1911, 143-148, https://doi.org/10.1177/ 0361198105191100114.

NWS, 2016: Experimental winter storm threat graphics. Accessed 1 July 2016, http://www.weather.gov/lwx/ExperimentalWinterStormThreat.

_ 2018 a: Automated Surface Observing System. NOAA, accessed 15 January 2018, http://www.nws.noaa.gov/asos/.
- 2018b: Cooperative Observer Program. NOAA, accessed 15 January 2018, http://www.nws.noaa.gov/om/coop/.

Pisano, P. A., L. C. Goodwin, and M. A. Rosetti, 2008: U.S. highway crashes in adverse road weather conditions. 24th Conf. on Interactive Information Processing Systems, New Orleans, LA, Amer. Meteor. Soc., 8.1, https://ams.confex.com/ ams/pdfpapers/133554.pdf.

Qui, L., 2008: Performance measurement for highway winter operations. Ph.D. dissertation, University of Iowa, 150 pp., accessed 10 March 2018, https://doi.org/10.17077/etd.08nzuotg.

Rasmussen, R. M., J. Vivekanandan, J. Cole, B. Myers, and C. Masters, 1999: The estimation of snowfall rate using visibility. J. Appl. Meteor., 38, 1542-1563, https://doi.org/10.1175/ 1520-0450(1999)038<1542:TEOSRU > 2.0.CO;2.

Rutz, J. J., and C. V. Gibson, 2013: Integration of a road surface model into NWS operations. Bull. Amer. Meteor. Soc., 94, 1495-1500, https://doi.org/10.1175/BAMS-D-12-00037.1.

RWMP, 2018: How do weather events impact roads? Federal Highway Administration, accessed 10 March 2018, https:// ops.fhwa.dot.gov/weather/q1_roadimpact.htm.

SPC, 2016: Sever weather risks. NWS, accessed 1 July 2016, http:// www.spc.noaa.gov/misc/about.html\#Severe\%20Weather\%20Risks.

_ 2018: Beaufort wind scale. NOAA, accessed 15 January 2018 http://www.spc.noaa.gov/faq/tornado/beaufort.html.

Strong, C., Y. Shvetsov, and J. Sharp, 2005: Development of roadway weather severity index. U.S. Department of Transportation Final Tech. Rep., 76 pp., https://westerntransportationinstitute.org/ research_projects/development-of-a-roadway-weather-severityindex-showcase-evaluation-16/.

Walker, C. L., 2018: Road weather impact based decision support applications: Developing a department of transportation winter severity index. Dissertations in Earth and Atmospheric Sciences, Ph.D. dissertation, University of Nebraska-Lincoln, 101 pp., https://digitalcommons.unl.edu/geoscidiss/101.

— , and M. R. Anderson, 2016: Cloud impacts on pavement temperature and shortwave radiation. J. Appl. Meteor. Climatol., 55, 2329-2347, https://doi.org/10.1175/JAMC-D-16-0094.1.

_ S. Hasanzadeh, B. Esmaeili, M. R. Anderson, and B. Dao, 2019: Developing a winter severity index: A critical review. Cold Reg. Sci. Technol., 160, 139-149, https://doi.org/10.1016/ j.coldregions.2019.02.005.

Walsh, C., 2016: Winter maintenance performance measure. Vaisala Inc. Rep. CDOT-2016-02, 22 pp.

WPC, 2018: Winter storm severity index. NOAA, accessed 15 January 2018, http://www.wpc.ncep.noaa.gov/wwd/wssi/wssi.php. 